\title{
Aerosol optical hygroscopicity measurements during the 2010 CARES campaign
}

\author{
D. B. Atkinson ${ }^{1}$, J. G. Radney ${ }^{1, *}$, J. Lum ${ }^{1}$, K. R. Kolesar ${ }^{2}$, D. J. Cziczo ${ }^{3}$, M. S. Pekour ${ }^{4}$, Q. Zhang ${ }^{5}$, A. Setyan ${ }^{5, * *}$, \\ A. Zelenyuk ${ }^{4}$, and C. D. Cappa ${ }^{2}$ \\ ${ }^{1}$ Department of Chemistry, Portland State University, Portland, OR, 97207, USA \\ ${ }^{2}$ Department of Civil and Environmental Engineering, University of California, Davis, CA, 95616, USA \\ ${ }^{3}$ Earth, Atmosphere and Planetary Sciences, Massachusetts Institute of Technology, Cambridge, MA, 02139, USA \\ ${ }^{4}$ Pacific Northwest National Laboratory, Richland, WA, 99352, USA \\ ${ }^{5}$ Department of Environmental Toxicology, University of California, Davis, CA, 95616, USA \\ *now at: Material Measurement Laboratory, National Institute of Standards and Technology, Gaithersburg, Maryland, \\ 20899, USA \\ *** now at: Empa, Swiss Federal Laboratories for Materials Science and Technology, 8600 Dübendorf, Switzerland
}

Correspondence to: D. B. Atkinson (atkinsdb@pdx.edu) and C. D. Cappa (cdcappa@ucdavis.edu)

Received: 11 October 2014 - Published in Atmos. Chem. Phys. Discuss.: 10 December 2014

Revised: 12 March 2015 - Accepted: 25 March 2015 - Published: 17 April 2015

\begin{abstract}
Measurements of the effect of water uptake on particulate light extinction or scattering made at two locations during the 2010 Carbonaceous Aerosols and Radiative Effects Study (CARES) study around Sacramento, CA are reported. The observed influence of water uptake, characterized through the dimensionless optical hygroscopicity parameter $\gamma$, is compared with calculations constrained by observed particle size distributions and size-dependent particle composition. A closure assessment has been carried out that allowed for determination of the average hygroscopic growth factors (GFs) at $85 \%$ relative humidity and the dimensionless hygroscopicity parameter $\kappa$ for oxygenated organic aerosol (OA) and for supermicron particles (defined here as particles with aerodynamic diameters between 1 and 2.5 microns), yielding $\kappa=0.1-0.15$ and $0.9-1.0$, respectively. The derived range of oxygenated $\mathrm{OA} \kappa$ values are in line with previous observations. The relatively large values for supermicron particles is consistent with substantial contributions of sea-salt-containing particles in this size range. Analysis of time-dependent variations in the supermicron particle hygroscopicity suggest that atmospheric processing, specifically chloride displacement by nitrate and the accumulation of secondary organics on supermicron particles, can lead to substantial depression of the observed GF.
\end{abstract}

\section{Introduction}

It is well established that atmospheric particles can have a strong influence on climate through their direct effect: scattering and absorption of solar and terrestrial radiation. Models must incorporate the net counteracting effects of cooling due to light scattering by particles and warming due to light absorption by greenhouse gases and particles to be successful at predicting global mean temperature. Uncertainties associated with climate forcing by particles remain sizable, and the negative forcing may be comparable to the collective positive radiative forcing from greenhouse gases (IPCC, 2013). Refinements of the linkage between the end results of models and measurements - particulate optical effects on the climate system as observed by in situ, ground-based, remote, and satellite measurements - and the presumptive sources of the particles are desirable to allow prediction of the effects of regulatory and other changes in future emissions.

Global climate models cannot currently fully represent the complex mixing state of particles indicated by in situ measurements. Therefore, such models typically utilize compositionally ensemble-averaged particle types with defined size distributions to represent the contributions from various sources. At the other extreme, some detailed models used for regional climate modeling and air quality simulation account 
more explicitly for particle dynamics, aging and mixing state (e.g., Riemer et al., 2010; Zaveri et al., 2010). In both simple and complex models, the extent of particulate water is determined by the local atmospheric relative humidity ( $\mathrm{RH}$ ) and the particle composition, the latter of which controls the particle hygroscopicity.

Particle composition is variable in space and time. Ambient measurements of submicron particle (i.e., particles with diameters $<1 \mu \mathrm{m}$ ) chemical composition indicate that both organic and inorganic components contribute substantially to the overall submicron particle burden (Jimenez et al., 2009). Compared to the major inorganic components, the properties of organic particulate matter - including hygroscopicity - are not as well established and are additionally much more variable. Much atmospheric organic particulate matter, or organic aerosol (OA), is secondary in origin, meaning that it is produced through chemical reactions. There are fewer studies that have explicitly investigated the hygroscopicity of ambient supermicron particles, i.e., those with diameters $>1 \mu \mathrm{m}$ (e.g., Hegg et al., 2008; Zhang et al., 2014).

One common method used to characterize particle hygroscopicity is through comparison between the light extinction or scattering coefficients ( $b_{\text {ext }}$ and $b_{\text {scat }}$, in $\mathrm{Mm}^{-1}$ ) measured at low (dry) and high relative humidity (RH). The extinction or scattering enhancement factors, $f_{\text {ext }}(\mathrm{RH})$ and $f_{\text {scat }}(\mathrm{RH})$, are defined as the ratio between the $b_{\text {ext }}$ or $b_{\text {scat }}$ measured at the high and low RH values. There are many measurements of $f(\mathrm{RH})$ reported in the literature, often focusing on differences in observed $f(\mathrm{RH})$ values between air masses containing different aerosol types (e.g., marine and urban) (e.g., Carrico et al., 2003; Massoli et al., 2009; Titos et al., 2014; Zhang et al., 2014; Zieger et al., 2010, 2013). Yet new, quantitative assessments of the relationship(s) between particle composition and $f(\mathrm{RH})$, and how these differ between different regions, remain necessary given that use of some of the most widely used aerosol optical models (e.g., OPAC) can still lead to substantial model/measurement discrepancies (Zieger et al., 2013). In particular, there remains a need to better understand the hygroscopic properties of OA and supermicron particles. In this study, the connections between particle composition, hygroscopicity, and optical properties (specifically scattering and extinction) are examined through optical closure based on observations made during the 2010 Carbonaceous Aerosols and Radiative Effects Study (CARES) field intensive (Zaveri et al., 2012). In particular, the observations are utilized to determine the hygroscopicity of specific particulate constituents, namely the oxygenated fraction of OA, termed OOA, and of supermicron particles.

\section{CARES campaign}

During June of 2010, a variety of aerosol and gas-phase species, as well as meteorological and radiative properties were measured as part of the CARES field intensive cam- paign in the Sacramento/Central Valley region of California (Zaveri et al., 2012). The CARES study was designed to take advantage of a persistent southwesterly flow pattern that transports pollutants from the Sacramento urban core and nearby Bay Area across the mostly agricultural areas in the Central Valley toward the forested foothills of the Sierra Nevada mountains (Fast et al., 2012). Two heavily instrumented ground sites were used to capture the evolution of the urban plume: one located just to the northeast of Sacramento, denoted T0, and one in the foothills of the Sierra Nevada in Cool, CA, referred to as T1 (Zaveri et al., 2012). Aircraft were also used to directly monitor the transport during periods predicted to have favorable meteorology. The results presented in this work are based on measurements obtained only at the two ground sites.

Much of the campaign was characterized by daytime westeast transport between the $\mathrm{T} 0$ and $\mathrm{T} 1$ sites, although there were occasional disruptions to the generalized flow pattern by shifts to northerly/northwesterly flow (Fast et al., 2012; Zaveri et al., 2012). The analysis here focuses primarily on periods with $\mathrm{T} 0 \rightarrow \mathrm{T} 1$ transport, but data from the entire campaign are considered. At least one of these periods (near the end of June) exhibits multi-day recirculation, either as a result of a daytime upslope/nocturnal downslope flow pattern or involving air mass lofting followed by subsidence near the west side of the valley. The recirculation period produced an extensively processed organic aerosol (Setyan et al., 2012).

\section{Experimental}

\subsection{Sampling}

Instruments were housed in dual, air-conditioned construction trailers with common aerosol and gas-phase manifolds. The detailed specifications of the aerosol inlet system are provided in Zaveri et al. (2012). Briefly, a high-throughput pump pulled air into a stainless steel aerosol inlet positioned between and above the trailers. The aerosol flow was split between the trailers and within the trailers into two separate $3 / 4$ inch stainless manifolds connected to high-flow return pumps. Each aerosol instrument station accessed the manifold through a 1/4 inch centerline pick-off using the instrument's pumping system. No intentional size selection was incorporated into the aerosol sampling mast or manifold system, but some of the instruments used size fractionation at their individual sampling points, as noted below.

\subsection{Optical property measurements}

\subsubsection{Cavity ring down-photoacoustic spectrometer}

Light extinction coefficients were measured at $\mathrm{T} 0$ at 405 and $532 \mathrm{~nm}$ using the UC Davis two-wavelength cavity ring down-photoacoustic spectrometer (CRD-PAS) instrument from 16-29 June 2010 (Langridge et al., 2011). Only 
data from the $532 \mathrm{~nm}$ CRD channels are used here, averaged to $10 \mathrm{~min}$. Four $532 \mathrm{~nm}$ channels were operated: low $\mathrm{RH}$ $(\sim 25 \%)$, mid RH $(\sim 75 \%)$, high RH $(\sim 85 \%)$ and a gasphase, filtered channel (at low RH). The gas-phase channel was used to correct for contributions from $\mathrm{NO}_{2}$ and $\mathrm{O}_{3}$ absorption. Gas-phase absorption was noticeable prior to the introduction of a guaiacol $+\mathrm{NaOH}$ denuder on 21 June, which successfully removed $\mathrm{NO}_{2}$; after this point the gas-phase absorption was zero. The estimated precision-based uncertainty for the $b_{\text {ext }}$ at $532 \mathrm{~nm}$, as determined from an Allan Variance analysis, was $0.27 \mathrm{Mm}^{-1}(1 \sigma, 2.2 \mathrm{~s})$ or $0.05 \mathrm{Mm}^{-1}(1 \sigma$, $60 \mathrm{~s}$ average). The CRD-PAS sampled behind a $\mathrm{PM}_{2.5}$ (aerodynamic diameter $<2.5 \mu \mathrm{m}$ ) URG Teflon-coated aluminum cyclone. Sampled particles were dried to $\sim 25 \% \mathrm{RH}$ in a flow-through Nafion dyer, after which the flow was split and two of the channels were re-humidified using custom flowthrough humidifiers. A time-series of the RH in the high-RH channel is shown in Fig. S4 in the Supplement. Relative humidity and temperature were measured within the CRD cavities by Vaisala sensors (HMP70) that were calibrated with saturated salt solutions before the campaign, giving an estimated absolute accuracy of $\pm 2 \%$.

\subsubsection{Nephelometer/humidigraph}

Light scattering by particles at multiple $\mathrm{RH}$ values was measured at the T1 site using a "humidigraph" (Pekour et al., 2012). The humidigraph is comprised of three nephelometers (Aurora Nephelometer, Model 1000) that measure $b_{\text {scat }}$ at $525 \mathrm{~nm}$ at one low and two higher RH values. Data were acquired at $1 \mathrm{~Hz}$ from 8-27 June 2010 and averaged to $10 \mathrm{~min}$. No intentional size cut was applied, although based on the configuration of the aerosol inlet it is unlikely that particles much larger than $\sim 3 \mu \mathrm{m}$ were sampled. No truncation correction has been applied to the observations. Based on the relationships provided in Müller et al. (2009) that relate the magnitude of the truncation correction to the scattering Ångström exponent, and calculations of the Ångström exponent based on the observed size distributions, the truncation correction for the Aurora nephelometer should be about $4 \%$. The influence of the truncation correction on the observed $f_{\text {sca }}(\mathrm{RH})$ will, however, be much smaller than $4 \%$ because it will approximately cancel when taking the ratio between the wet and dry particle scattering; we estimate that not accounting for instrument truncation will have influenced the $f_{\text {sca }}(\mathrm{RH})$ values by $<1 \%$.

The instruments were operated with one of two distinct configurations. In one (8-17 June), the three nephelometers were operated in parallel, with the aerosol stream being split and sampled respectively (i) through a Nafion dryer (low RH), (ii) without alteration (mid RH), and (iii) through a water-cooled line (high RH). In the second configuration (21-27 June), the entire aerosol stream was first humidified, after which $1 / 3$ of the flow was split to a high-RH nephelometer and the remaining flow was passed through a Nafion dryer, after which $1 / 2$ of this flow was directed to a mid-RH nephelometer while the remaining flow was passed through a second Nafion drier and on to a low-RH nephelometer. The second configuration provided for more useful ranges of RH (since the original configuration often resulted in nearcoincidence of the low and ambient $\mathrm{RH}$ channels) and assured that salt-like aerosols would be on the high $\mathrm{RH}$ branch (efflorescence) of the hysteresis curve. A time-series of the $\mathrm{RH}$ in the high-RH channel is shown in Fig. S4; the average value during the second configuration was $72 \% \pm 9 \%$, with the range resulting from large diurnal temperature swings in the trailer. The average low $\mathrm{RH}$ was $29 \% \pm 4 \%$. Measurements made using the second configuration are used in the primary analysis below, although results from 15 June (using the initial configuration) will be considered as a specific case study. The RH, temperature and pressure were measured independently by sensors within each of the nephelometers.

\subsubsection{Hygroscopicity characterization}

The low and highest RH $b_{\text {ext }}$ and $b_{\text {scat }}$ observations at T0 and $\mathrm{T} 1$, respectively, have been used to determine a time-series of $f(\mathrm{RH})$. The $f(\mathrm{RH})$ values have been converted to the dimensionless extinction or scattering hygroscopicity parameters (Massoli et al., 2009; Quinn et al., 2005), $\gamma_{\text {ext }}$ and $\gamma_{\text {scat }}$, as

$$
\gamma=-\frac{\ln [f(\mathrm{RH})]}{\ln \left[\frac{100-\mathrm{RH}_{\mathrm{low}}}{100-\mathrm{RH}_{\text {high }}}\right]} .
$$

The use of $\gamma$ assumes a power-law dependence of extinction and scattering on $\mathrm{RH}$, which arises mostly from the increase in particle size with water uptake. $\gamma$ also implicitly assumes continuous water uptake. Whereas $f(\mathrm{RH})$ is dependent on the absolute $\mathrm{RH}$ values, $\gamma$ is reasonably independent of $\mathrm{RH}$ and thus provides a more robust characterization of the fundamental particle hygroscopicity.

\subsection{Particle composition measurements}

\subsubsection{Ensemble aerosol mass spectrometry}

Mass concentrations of submicron non-refractory particulate matter (NR-PM) were measured at both T0 and T1 using Aerodyne high resolution time-of-flight aerosol mass spectrometers (HR-ToF-AMS, henceforth AMS) (Canagaratna et al., 2007; DeCarlo et al., 2006). NR-PM components measured by the AMS include the major inorganic species sulfate, nitrate and ammonium (along with some forms of chlorine), and OA. The AMS measures ensemble-average particle composition for particles with vacuum aerodynamic diameters $\left(d_{\mathrm{p}, \mathrm{va}}\right)$ between $\sim 30$ and $1000 \mathrm{~nm}$. At T1, sizedependent composition was also measured. Assuming spherical particles, $d_{\mathrm{p}, \mathrm{va}}$ is related to the particle mobility diameter $\left(d_{\mathrm{p}, \mathrm{m}}\right)$ through particle density $\rho_{\mathrm{p}}$ (assuming spherical 
particles) (DeCarlo et al., 2004). A $d_{\mathrm{p}, \mathrm{va}}=1000 \mathrm{~nm}$ corresponds to a $d_{\mathrm{p}, \mathrm{m}}$ of $670 \mathrm{~nm}$ for $\rho_{\mathrm{p}}=1.5 \mathrm{~g} \mathrm{~cm}^{-3}$ and $500 \mathrm{~nm}$ for $\rho_{\mathrm{p}}=2 \mathrm{~g} \mathrm{~cm}^{-3}$. The calculation of optical properties depends on geometric (physical) diameter, which for spherical particles is equal to $d_{\mathrm{p}, \mathrm{m}}$ and not $d_{\mathrm{p}, \mathrm{va}}$. Therefore, with respect to the measurement of particle composition relevant to the calculation of optical properties, it is more precise to state that the AMS measures approximately sub- $670 \mathrm{~nm}$ particles, not submicron particles. However, for simplicity and consistency with the literature we will refer to particles with $d_{\mathrm{p}, \mathrm{va}}<1000 \mathrm{~nm}$ as submicron.

Further characterization of the OA was obtained via positive matrix factorization (PMF), from which different OA "types" (or factors) were identified (Zhang et al., 2011). During CARES, three major factors were identified at T0 and T1. At T0, there were two less-oxygenated factors and one highly oxygenated factor, while at $\mathrm{T} 1$ there was only one less-oxygenated factor but two highly oxygenated factors (Setyan et al., 2012). Since the hygroscopicity of the two less oxygenated OA factors at $\mathrm{T} 0$ and the two highly oxygenated factors at $\mathrm{T} 1$ are likely similar they have been combined into one factor in each case. Thus, only two OA types are considered at each site, one less oxygenated, referred to as hydrocarbon-like OA (HOA), and one highly oxygenated, referred to as OOA.

\subsubsection{Single Particle Mass Spectrometry}

Two different types of single particle mass spectrometers were deployed, one at T0 and one at T1. At T1, the Particle Analysis by Laser Mass Spectrometry (PALMS) instrument was deployed (Cziczo et al., 2006). PALMS samples particles through an aerodynamic lens into a vacuum chamber where individual particles are detected and sized using dual continuous $532 \mathrm{~nm}$ lasers after which $193 \mathrm{~nm}$ light is used to ablate and ionize the particles. The resulting ions are analyzed using a ToF-MS. PALMS detects and characterizes the composition, including refractory components, of particles in the size range $300 \mathrm{~nm}<d_{\text {p,va }}<2000 \mathrm{~nm}$. Single particles are classified according to the predominant ions in their mass spectra. PALMS provides a semi-quantitative indication of particle mixing state by identifying differences in composition between individual particles (Murphy et al., 2006).

At T0 SPLAT II was deployed (Zelenyuk et al., 2009). SPLAT II works similarly to the PALMS, with a key difference being that SPLAT II uses a $\mathrm{CO}_{2}$ laser to first desorb the non-refractory fraction of individual particles and a $193 \mathrm{~nm}$ excimer laser to ionize the produced gas-phase plume and ablate the refractory particle fraction. For spherical particles, SPLAT II has nearly $100 \%$ detection efficiency over the range $125<d_{\mathrm{p}, \mathrm{va}}<600 \mathrm{~nm}$, with $50 \%$ cut-off at $d_{\mathrm{p}, \mathrm{va}}=85 \mathrm{~nm}$. Above and below this size range, the detection efficiency falls off, although particles with diameters up to a few microns can be detected. For non-spherical particles, the detection efficiency can be substantially lower due to divergence of the particle beam. Characterized particles are classified according to the mass spectra. SPLAT-identified particle types included soot, biomass burning (BB), primary OA (POA), hydrocarbon-like (HC), sea salt (SS), dust, two types of amine containing particles (amine Type I and Type II) and mixtures of organics and inorganics, predominately sulfate, with varying relative abundances. The mixed sulfate/organic particles are referred to as Sulfate + OA Type I through Type IV, signifying mixtures from $75 \%$ sulfate down to less than $5 \%$ sulfate respectively. Because particles with different compositions may exist in different size ranges and have different shapes, the detection efficiencies could vary with type (especially for the dust and sea salt that tend to be present in larger particles). For comparison with the AMS, the size distributions of the sulfate/OA particle types were used to estimate the size-dependent distribution of sulfate mass and OA mass. The size-dependent mass of each particle type was estimated from the measured particle-phase densities and particle size (assuming spherical particles), and the relative amounts of OA and sulfate mass in each particle size bin were determined from their relative ratios, as further described in Sect. 4.

For both the T0 and $\mathrm{T} 1$ sites, the single particle measurements were the only instruments deployed that provide information on the composition of supermicron particles. This data limitation has implications as to how the supermicron particle composition is treated in the optical calculations discussed in Sect. 4.

\subsubsection{Refractory black carbon}

Refractory black carbon (rBC) mass concentrations were measured at both sites using single particle soot photometers (SP2; DMT, Inc.; Schwarz et al., 2010). The SP2s were calibrated using mobility size-selected Aquadag (Acheson, Inc.) graphite-containing particles and the known relationship between mobility diameter and per-particle mass for this particle type. The rBC concentrations have been adjusted to account for the higher sensitivity of the SP2 to Aquadag than to other black carbon types (in particular, to diesel soot; Laborde et al., 2012a). The CARES SP2 instruments measured $\mathrm{rBC}$-containing particles with volume equivalent core diameters $\left(d_{\mathrm{p}, \mathrm{ved}}\right)$ between 30 and $400 \mathrm{~nm}$, although the SP2 is not fully quantitative for particles with $d_{\mathrm{p}, \text { ved }}<\sim 100 \mathrm{~nm}$ (Laborde et al., 2012b) and thus the BC concentration measured by the SP2 is a lower limit (Cappa et al., 2014).

\subsection{Size distribution measurements}

Submicron dry particle mobility diameter $\left(d_{\mathrm{p}, \mathrm{m}}\right)$ size distributions were measured at $\mathrm{T} 0$ and $\mathrm{T} 1 \mathrm{using}$ scanning mobility particle sizers (SMPS) comprised of a charge neutralizer, differential mobility analyzer (DMA) and a condensation particle counter (CPC). The SMPS at T0 was a commercial 
TSI system (3081 DMA column and model 3775 CPC). The SMPS used at T1 is described in Setyan et al. (2014). The SMPS data were corrected for multiply charged particles and diffusional losses within the instruments. At T0, the SMPS was configured to measure particles over a size range of 12 to $737 \mathrm{~nm}$, while the T1 instrument measured from 8 to $858 \mathrm{~nm}$.

Supermicron dry particle aerodynamic diameter $\left(d_{\mathrm{p}, \mathrm{a}}\right)$ size distributions were measured at both sites over the size range 542 to $20000 \mathrm{~nm}$ using aerodynamic particle sizers (APS; Model 3321, TSI, Inc.). The measured aerodynamic size distributions were converted to $d_{\mathrm{p}, \mathrm{m}}$ equivalent size distributions assuming spherical particles and a constant density of $2.0 \mathrm{~g} \mathrm{~cm}^{-3}$ (roughly compatible with either an inferred dust or sea-salt composition) with

$d_{\mathrm{p}, \mathrm{m}}=d_{\mathrm{p}, \mathrm{a}} \sqrt{\frac{1}{\rho_{\mathrm{p}}} \frac{C_{\mathrm{c}}\left(d_{\mathrm{p}, \mathrm{a}}\right)}{C_{\mathrm{c}}\left(d_{\mathrm{p}, \mathrm{m}}\right)}}$,

where $C_{\mathrm{c}}$ is the Cunningham slip correction factor (DeCarlo et al., 2004). Because $C_{\mathrm{c}}$ depends on $d_{\mathrm{p}, \mathrm{m}}$, Eq. (2) must be solved iteratively. For reference, a particle with $d_{\mathrm{p}, \mathrm{a}}=2500 \mathrm{~nm}$ and $\rho_{\mathrm{p}}=2 \mathrm{~g} \mathrm{~cm}^{-3}$ has a $d_{\mathrm{p}, \mathrm{m}}=1745 \mathrm{~nm}$ and a particle with $d_{\mathrm{p}, \mathrm{a}}=1000 \mathrm{~nm}$ and $2 \mathrm{~g} \mathrm{~cm}^{-3}$ has a $d_{\mathrm{p}, \mathrm{m}}=685 \mathrm{~nm}$. It should be noted that $d_{\mathrm{p}, \mathrm{a}}$ is not equivalent to the $d_{\mathrm{p}, \mathrm{va}}$ measured by the AMS, SPLAT II and PALMS.

The SMPS and converted APS size distributions were merged into a single mobility-diameter size distribution (Fig. 1c and f). The SMPS measurements were used for particles with diameters $<737 \mathrm{~nm}$ and the APS measurements were used for larger particles. We will refer to particles with $d_{\mathrm{p}, \mathrm{m}}<737 \mathrm{~nm}$ as "submicron" and with $1700 \mathrm{~nm}>d_{\mathrm{p}, \mathrm{m}}>737 \mathrm{~nm}$ as "supermicron", since the sub/supermicron distinction is typically based on aerodynamic diameter.

The merged size distributions were ultimately used as input to the Mie theory calculations (see next section), and thus the assumption regarding the particle density will have some influence on the calculated scattering. It is unlikely that the particle density is much larger than $2 \mathrm{~g} \mathrm{~cm}^{-3}$. Had smaller values been assumed, the shift in $d_{\mathrm{p}, \mathrm{a}}$ to $d_{\mathrm{p}, \mathrm{m}}$ would have been smaller and, consequently, the calculated scattering would be increased. Had a density of 1.75 or $1.5 \mathrm{~g} \mathrm{~cm}^{-3}$ been assumed, the calculated scattering would have increased on average by $\sim 8$ or $21 \%$, respectively. This is important to keep in mind in the context of the dry particle optical closure presented below. However, a density of $2 \mathrm{~g} \mathrm{~cm}^{-3}$ gave the best overlap with the SMPS distribution, on average, and thus was chosen here; the average SMPS and APS mobility size distributions are shown for the T0 site in Fig. S1 for reference. Additionally, since the hygroscopicity measurements result from a ratio of extinction or scattering values, these effects largely cancel out and lead to only minor changes in the derived hygroscopicity parameters.

The APS at T0 malfunctioned after 22 June 21:00 PST, limiting the period over which observations of extensive properties, such as $b_{\text {ext }}$, at this site can be directly compared with calculations. However, calculations of intensive properties, such as $f(\mathrm{RH})$ or $\gamma_{\mathrm{RH}}$, exhibit less sensitivity to the exact nature of the size distribution since the intensive properties depend on the calculation of ratios of extensive properties; this is especially true when $d_{\mathrm{p}, \mathrm{m}}>\sim 700 \mathrm{~nm}$. This lack of sensitivity is exploited here to facilitate comparison of calculated and observed $\gamma_{\mathrm{RH}}$. The measured supermicron size distribution shape was constant in time over the measurement period during which the APS was operating properly, with only the total particle concentration varying. A synthetic supermicron size distribution for the missing data period was therefore determined by comparing the observed and calculated dry particle $b_{\text {ext }}$ (see next section). Specifically, the shape of the distribution was assumed equal to the campaign average (Fig. S1), and the number concentration of particles with $d_{\mathrm{p}, \mathrm{m}}>737 \mathrm{~nm}$ was scaled such that the observed and calculated dry $b_{\text {ext }}$ agreed to within $1 \%$. The final, merged size distribution after 22 June is comprised of actual SMPS measurements and the synthetic APS distribution. Importantly, small mismatches in the exact shape of the supermicron particle size distribution have only a small effect on the derived hygroscopicity.

\section{Optical property calculations}

\subsection{General methodology}

Time-series of $b_{\text {ext }}$ and $b_{\text {scat }}$ have been calculated from Mie theory for both low and high RH conditions using the measured dry particle size distribution and composition as model inputs. The combined low $\mathrm{RH}$ and high $\mathrm{RH}$ calculations have been used to calculate $f(\mathrm{RH})$ and $\gamma$ values, which can be compared with the observations. The calculations require specification of the amount of particle phase water and the associated particle growth, which depends on the particle composition. The hygroscopicity of the various particulate components varies and is reasonably well-known for some components (e.g., ammonium sulfate, ammonium nitrate, black carbon, and hydrocarbon-like OA) but is not as well established for others (e.g., OOA and supermicron particles). Here, the hygroscopicity of the "unknown" components, specifically of OOA (Sect. 5.2.3) and of supermicron (Sect. 5.2.4) particles, have been determined through comparison between the observed and calculated $\gamma$ values. Further details of the general methodology used here are presented below.

The $b_{\text {ext }}$ and $b_{\text {scat }}$ have been calculated from the observed dry particle size distributions using a numerical implementation of spherical particle Mie theory (Bohren and Huffman, 1983). At each point in time extinction and scattering cross sections, $\sigma_{\text {ext }}$ and $\sigma_{\text {scat }}$, were calculated for each median diameter of the appropriate (i.e., $\mathrm{RH}$-adjusted) bin in the size distribution $\left(d_{\mathrm{p}, \mathrm{m}, \mathrm{RH}}\right)$ and multiplied by the observed particle 

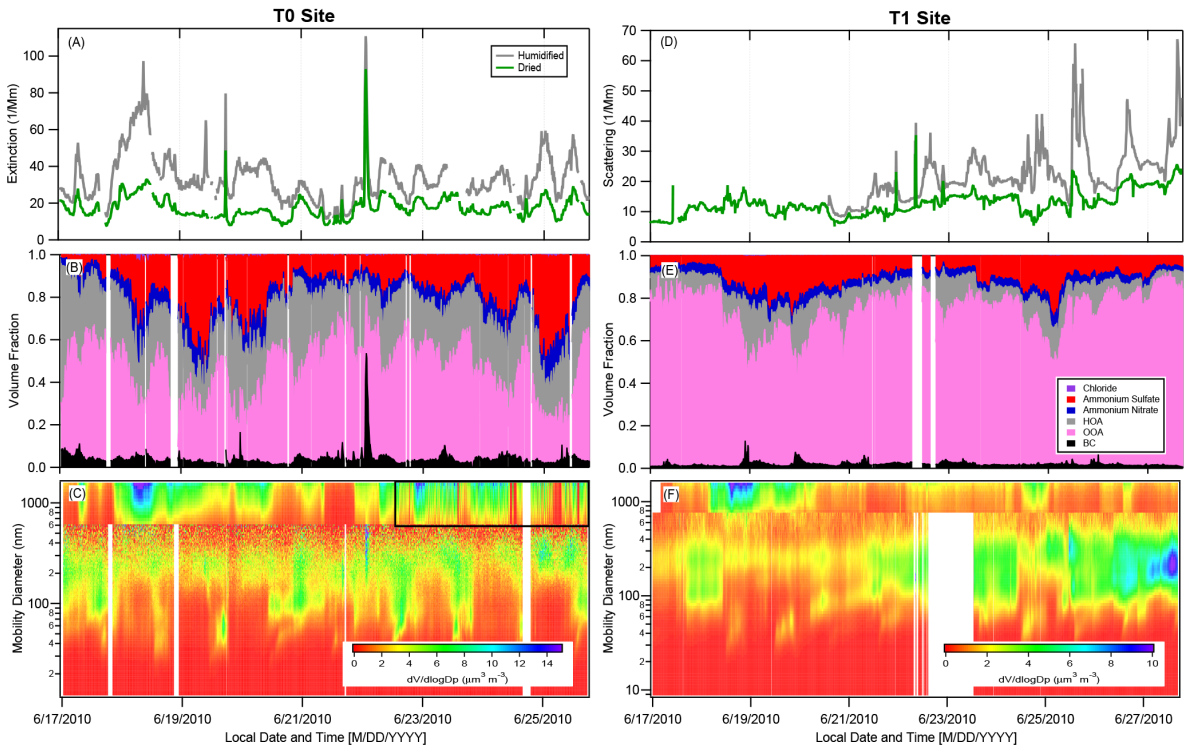

Figure 1. Overview time-series data of $b_{\text {ext }}$ at T0 (left panels) and $b_{\text {scat }}$ at T1 (right panels) for both humidified and dried particles (a) and (d), volume fraction of the various submicron components, exclusive of water (b) and (e), and composite volume-weighted size distributions (c) and (f). Note that neither the vertical nor the horizontal scales are the same between the two sites/sets of panels. The black box around the last portion of the large particle size distribution at T0 (c) indicates the time period during which a synthetic size distribution was used, as described in the text.

number distribution, and the product was then integrated over size to produce the bulk optical coefficients:

$b_{\mathrm{ext}}=\int_{d_{\mathrm{p}, \mathrm{m}, \text { min }}}^{d_{\mathrm{p}, \mathrm{m}, \max }} \sigma_{\mathrm{ext}}\left(d_{\mathrm{p}, \mathrm{m}, \mathrm{RH}}\right) \cdot \frac{\mathrm{dN}}{\operatorname{dlog}\left(d_{\mathrm{p}, \mathrm{m}, \mathrm{RH}}\right)} \mathrm{d} \log \left(d_{\mathrm{p}, \mathrm{m}, \mathrm{RH}}\right)$.

Submicron and supermicron particles are treated separately (i.e., as having distinct properties), but in similar manners. Bulk-average real refractive indices $(n)$ were calculated at each point in time using volume mixing rules, specifically:

$n_{\mathrm{tot}}=\sum_{i} \mathrm{VF}_{i} \cdot n_{i}$

where $\mathrm{VF}_{i}$ is the volume fraction of component $i$ in each particle, including water, and the species-specific $n$ values are given in Table 1. For submicron particles the dry VF values were determined from the measured mass concentrations of the individual PM components using the densities given in Table 1 . Dry supermicron particles were assumed to have a constant real refractive index (Table 1). This assumption does not account for variations in the refractive index that can result from variations in the supermicron particle composition (e.g., sea salt vs. dust). Particulate water volume fractions $\left(\mathrm{VF}_{\mathrm{H}_{2} \mathrm{O}}\right)$ were determined based on the measured particle composition, as discussed further below. The base-case assumes that the particles do not absorb light. The influence of particle light absorption on the calculations is discussed separately in Sect. 5.2.7.
Table 1. Species properties used in model calculations.

\begin{tabular}{|c|c|c|c|c|}
\hline PM Component & Real $n_{i}$ & $\begin{array}{l}\text { Density } \\
\left(\mathrm{g} \mathrm{cm}^{-3}\right)\end{array}$ & $\kappa^{\mathrm{b}}$ & $\begin{array}{r}\text { GF } \\
(85 \%)^{\mathrm{c}}\end{array}$ \\
\hline$\left(\mathrm{NH}_{4}\right)_{2} \mathrm{SO}_{4}$ & 1.52 & 1.77 & 0.61 & 1.63 \\
\hline $\mathrm{NH}_{4} \mathrm{NO}_{3}$ & 1.5 & 1.73 & 0.67 & 1.67 \\
\hline $\mathrm{BC}$ & 1.9 & 1.8 & 0 & 1.00 \\
\hline Chloride & 1.55 & 2.17 & 1.12 & 1.93 \\
\hline HOA & 1.45 & $1^{\mathrm{d}}$ & 0.006 & 1.02 \\
\hline OOA & 1.49 & $1.4^{\mathrm{d}}$ & $\mathrm{e}$ & $\mathrm{e}$ \\
\hline Supermicron $^{\mathrm{f}}$ & $1.7^{\mathrm{d}}$ & $2.1^{\mathrm{d}}$ & $\mathrm{e}$ & $\mathrm{e}$ \\
\hline Water & 1.33 & 1.0 & $\mathrm{n} / \mathrm{a}$ & $\mathrm{n} / \mathrm{a}$ \\
\hline
\end{tabular}

${ }^{\mathrm{a}}$ Haynes and Lide (2014); ${ }^{\mathrm{b}}$ Petters and Kreidenweis (2007); ${ }^{\mathrm{c}}$ calculated from $\kappa$ values; ${ }^{\mathrm{d}}$ assumed; ${ }^{\mathrm{e}}$ adjustable; ${ }^{\mathrm{f}}$ technically, $d_{\mathrm{p}, \mathrm{m}}>737 \mathrm{~nm}$.

The RH-specific physical growth factors $\left(\mathrm{GF}=d_{\mathrm{p}, \mathrm{m}, \text { wet }} / d_{\mathrm{p}, \mathrm{m}, \mathrm{dry}}\right)$ associated with each submicron NR-PM component $\left(\mathrm{GF}_{i}\right)$ were determined based on the hygroscopicity parameter, $\kappa$, of the individual component using the relationship (Petters and Kreidenweis, 2007):

$\frac{\mathrm{RH}}{\exp \left(\frac{A}{d_{\mathrm{p}, \mathrm{m}, \mathrm{dry} \cdot \mathrm{GF}}}\right)}=\frac{\mathrm{GF}^{3}-1}{\mathrm{GF}^{3}-(1-\kappa)}$,

where $d_{\mathrm{p}, \mathrm{m} \text {,dry }}$ is the dry particle diameter, $\mathrm{RH}$ is the measured (low or high) RH and $A=2.09 \mathrm{~nm}$ is a constant that includes the surface tension of water and other physical constants. Values of $\kappa$ for the inorganic salts, black carbon and HOA are specified based on the literature (Table 1), while 
$\kappa$ values for both OOA and supermicron particles are determined through optical closure, discussed in Sect. 5.2. The overall GF of the particles at the measured RH were then calculated from volume mixing rules:

$\mathrm{GF}_{\text {tot }}(\mathrm{RH})=\left(\sum_{i} \mathrm{VF}_{i} \cdot\left(\mathrm{GF}_{i}(\mathrm{RH})\right)^{3}\right)^{\frac{1}{3}}$

where the summation is taken over all non-water components. The wet particle diameters for use in the Mie calculations (Eq. 4) are

$d_{\mathrm{p}, \mathrm{m}, \mathrm{RH}}=\mathrm{GF}_{\mathrm{tot}}(\mathrm{RH}) \cdot d_{\mathrm{p}, \mathrm{m}, \mathrm{dry}}$,

and the resulting $\mathrm{VF}_{\mathrm{H}_{2} \mathrm{O}}$ are

$\mathrm{VF}_{\mathrm{H}_{2} \mathrm{O}}=1-\left(1 / \mathrm{GF}_{\mathrm{tot}}\right)^{3}=\frac{D_{\mathrm{p}, \mathrm{m}, \mathrm{RH}}^{3}-D_{\mathrm{p}, \mathrm{m}, \mathrm{dry}}^{3}}{D_{\mathrm{p}, \mathrm{m}, \mathrm{RH}}^{3}}$.

\subsection{Accounting for size-dependent composition and mixing state}

Particle composition varies with particle size and between individual particles in a given size range (Zaveri et al., 2012). Such variations can lead to size-dependent GFs and $\mathrm{VF}_{\mathrm{H}_{2} \mathrm{O}}$ values, which can influence the calculated optical properties. Here, three different approaches to accounting for variations in composition with dry particle size or mixing state are compared. The first approach assumes that particles are internally well mixed with a size-independent composition within a given mode (sub vs. supermicron). For the submicron particles, the bulk composition is taken as the sum of the measured NR-PM and BC. The second approach similarly assumes a size-independent (but mode-specific) composition, but with the various submicron components being externally mixed from each other, existing in single component particles. Internal vs. external mixing assumptions can influence the calculated extinction for the humidified particles because internally mixed particles will all grow by the same amount due to water uptake, while externally mixed particles with the same dry size will grow to different extents upon humidification. For example, consider two $150 \mathrm{~nm}$ diameter particles comprised of two components $\mathrm{A}$ and $\mathrm{B}$ with equal volume fractions but where component $\mathrm{A}$ has a $\mathrm{GF}=1$ and component $\mathrm{B}$ has a $\mathrm{GF}=2$. Both particles will grow to be $225 \mathrm{~nm}$ as an internal mixture, but one will grow to $150 \mathrm{~nm}$ and the other to $300 \mathrm{~nm}$ as an external mixture of $\mathrm{A}$ and $\mathrm{B}$, respectively. Extinction and scattering do not vary monotonically with particle size, and thus these two mixing cases do not give equivalent results.

The third approach, referred to as the size-dependent composition model, accounts for size-dependent variations in submicron particle composition. Both the AMS (for T1) and the SPLAT II (for T0) measurements indicate that particle composition did vary with particle size and that this variation was time-dependent (e.g., with the time of the day and from day to day). Ideally, highly time-resolved, quantitative size-dependent composition measurements would be used in these calculations. However, given site-to-site differences in measurement/data availability, the analysis here uses the campaign average size-dependent composition for each site. The use of the campaign-average information allows for a first-order assessment of how variations in particle composition with size influence the calculated optical properties. (Again, because of data availability and concerns about variable detection efficiency of larger particles, the supermicron mode was assumed to have a size-independent composition.)

The basic framework for the size-dependent submicron calculations, illustrated schematically in Fig. 2, is as follows: first, normalized campaign-average mass-weighted size distributions for each particle component (e.g. OA, ammonium nitrate, and ammonium sulfate) or particle type were determined. These component-specific distributions are used to determine the fraction of each component as a function of particle size. The fractions are used as size-dependent weighting-factors to apportion the measured ensemble particle composition of each component at each point in time onto the observed size distribution at that time point. This yields a time-series of composition-weighted size distributions with an assumption of completely internally mixed particles for each size bin. These composition-weighted size distributions are then used to calculate size-dependent GFs and refractive indices for use in the calculation of $b_{\text {ext }}$ and $b_{\text {sca. }}$. Since the measurements used to assess the size-dependent composition differ between the two sites, differences in the specific methods used to determine the average size-dependent composition between sites are discussed in more detail below.

For the $\mathrm{T} 1$ site, the normalized campaign-average sizedependent composition for submicron particles was determined from the AMS particle time-of-flight measurements (Setyan et al., 2012). It was assumed that the BC, HOA and OOA components had similar average size distributions, based on the general similarity of the observed size distributions for the AMS tracer ions $m / z=44$ and $m / z=43$, which exhibit some correspondence with OOA and HOA, respectively (Setyan et al., 2012). The bulk particle composition at each point in time was also determined from the AMS measurements, with the exception of $\mathrm{BC}$, which comes from the SP2 measurements. The measured $\mathrm{NH}_{4}^{+}$was apportioned on a molar basis between $\mathrm{NO}_{3}^{-}, \mathrm{SO}_{4}^{2-}$ and $\mathrm{Cl}^{-}$to produce $\mathrm{NH}_{4} \mathrm{NO}_{3},\left(\mathrm{NH}_{4}\right)_{2} \mathrm{SO}_{4}$ and $\mathrm{NH}_{4} \mathrm{Cl}$; residual $\mathrm{NH}_{4}^{+}$was negligible (Setyan et al., 2012).

As noted above, for T0 size-dependent submicron composition data from the AMS were not available. Therefore, the SPLAT II data were used to obtain the variation in composition with size within the submicron range and to determine the normalized size-dependent composition. To provide some consistency between $\mathrm{T} 0$ and $\mathrm{T} 1$, the SPLAT particle types were mapped onto the AMS + SP2-derived component types as follows: HOA is equivalent to the sum 

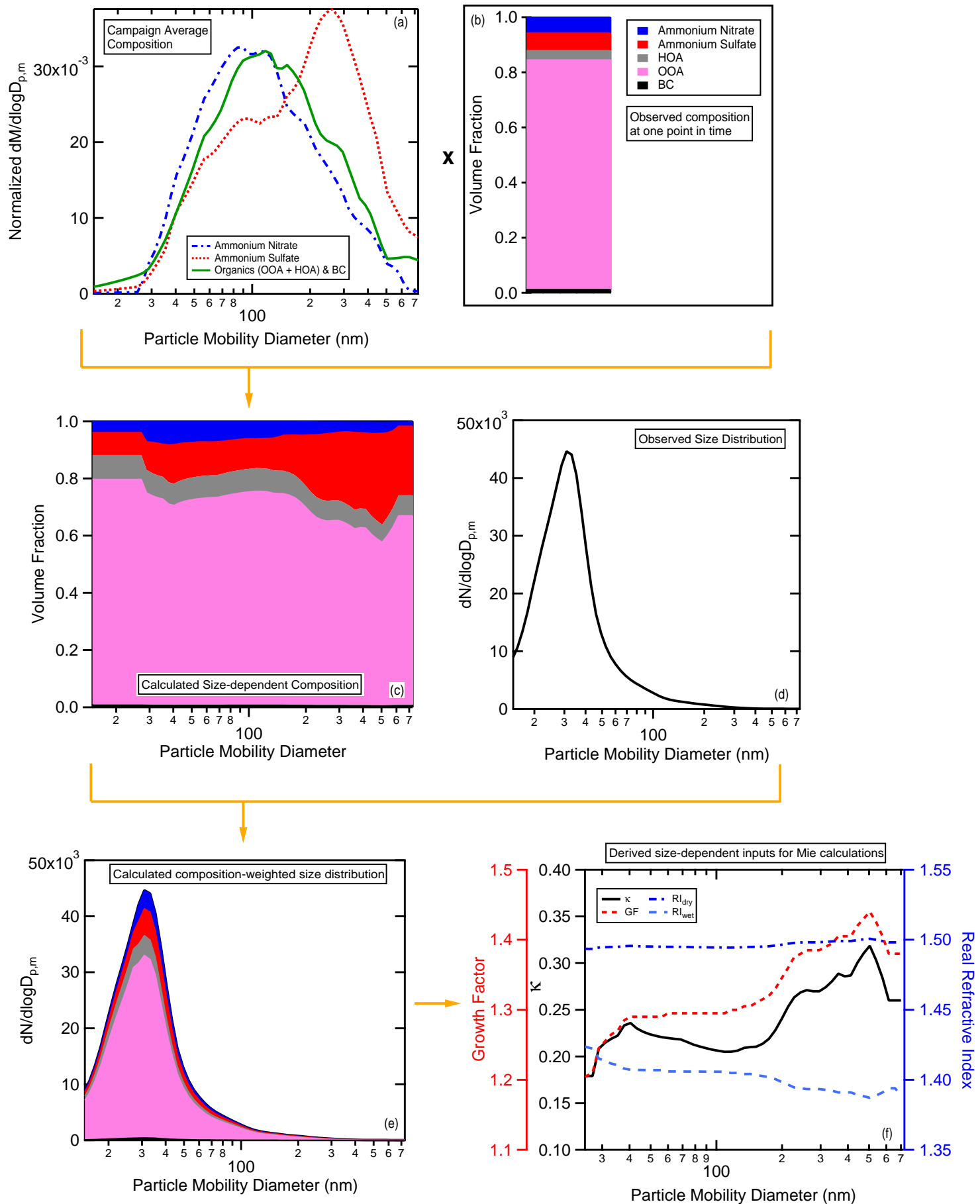

Figure 2. Schematic of the process for determining size-dependent hygroscopic growth factors and real refractive indices. The top panels (a and b) illustrate how the observed campaign-average size-dependent normalized particle composition and the time-dependent particle composition are combined to yield the time- and size-dependent particle composition (c). The resulting size-dependent particle composition is combined with the time-dependent size distribution (d) to yield a time-dependent size distribution with size-dependent composition (e). The resulting size distribution is then used to determine size-dependent growth factors, $\kappa$ values and real refractive indices $(\mathbf{f})$.

of the SPLAT II POA, BB, and HC categories; BC is equivalent to the SPLAT II soot type; inorganic ions (excluding sea salt and dust) are equivalent to SPLAT II sulfate; oxygenated
OA is equivalent to SPLAT II OA. SPLAT II reports sulfate and $\mathrm{OA}$ as mixed particle types of varying relative composition, and thus the sulfate and OA modes were estimated from 
weighted sums of the mixed sulfate + OA particle types. For example, the size distribution for the 50/50 sulfate + OA mixed particle type is split into two individual sulfate and organic size distributions, with half the mass in one and half in the other. The total sulfate (really, total inorganics) and OA distributions are then determined from the sum over all of the different sulfate + OA particle types. The overall distribution is then determined by assuming that the particles are internally mixed within each size bin. A cartoon illustrating this process is shown in Fig. S2. This last assumption (internal mixing within a given size bin) discards some of the available information from the SPLAT II measurements on mixing state, but is done to facilitate comparison with the AMS results from T1. Comparison of the size-independent internally mixed vs. externally mixed calculations provides some indication of the limitations of this simplification.

It is assumed in all cases that the supermicron composition is size-independent, a simplification that has been made to account for limitations regarding time-dependent variations in the supermicron particle composition. Unless otherwise stated, results of calculations in Sect. 5.2 have used the size-dependent submicron composition method. The three approaches (external mixing, size-independent internally mixed and size-dependent internally mixed) are compared in Sect. 5.2.6.

\section{Results and discussion}

\subsection{Overview of observations}

Time series for the dried $(\mathrm{RH}<40 \%)$ and humidified (RH $\sim 85 \%)$ particle extinction $(532 \mathrm{~nm})$ or scattering $(525 \mathrm{~nm})$, the submicron particle composition as volume fractions, and the volume-weighted particle size distributions are shown in Fig. 1 for both T0 and T1. At T1, the submicron particle composition is dominated by OOA (Fig. 1e), as noted by Setyan et al. (2012). At T0, organics also comprise a large fraction of the total submicron PM, although HOA/OA is larger than at $\mathrm{T} 1$ (Fig. 1b). Further, there are periods where the OA fraction is only $\sim 50 \%$ of the submicron PM mass at $\mathrm{T} 0$, while the OA fraction is always $>70 \%$ at $\mathrm{T} 1$. At both $\mathrm{T} 0$ and $\mathrm{T} 1$ the submicron contribution to the overall $\mathrm{PM}_{2.5}$ particle volume concentration tends to be larger than for supermicron components, although there are periods where the supermicron components contribute substantially (Figs. 1c, f and S3), and it should be noted that contributions from even larger particles $\left(d_{\mathrm{p}, \mathrm{a}}>2.5 \mu \mathrm{m}\right)$ can be substantial (Kassianov et al., 2012).

Time-series of the observed optical hygroscopicity parameter, $\gamma$, for T0 and $\mathrm{T} 1$ are shown in Fig. 3a and c. Values of $\gamma$ varied from as low as $\sim 0.2$ to as high as $\sim 1.0$. The values of $\gamma$ at T0 and T1 are similar during the latter part of the study (22 through 28 June) when transport and recircula-
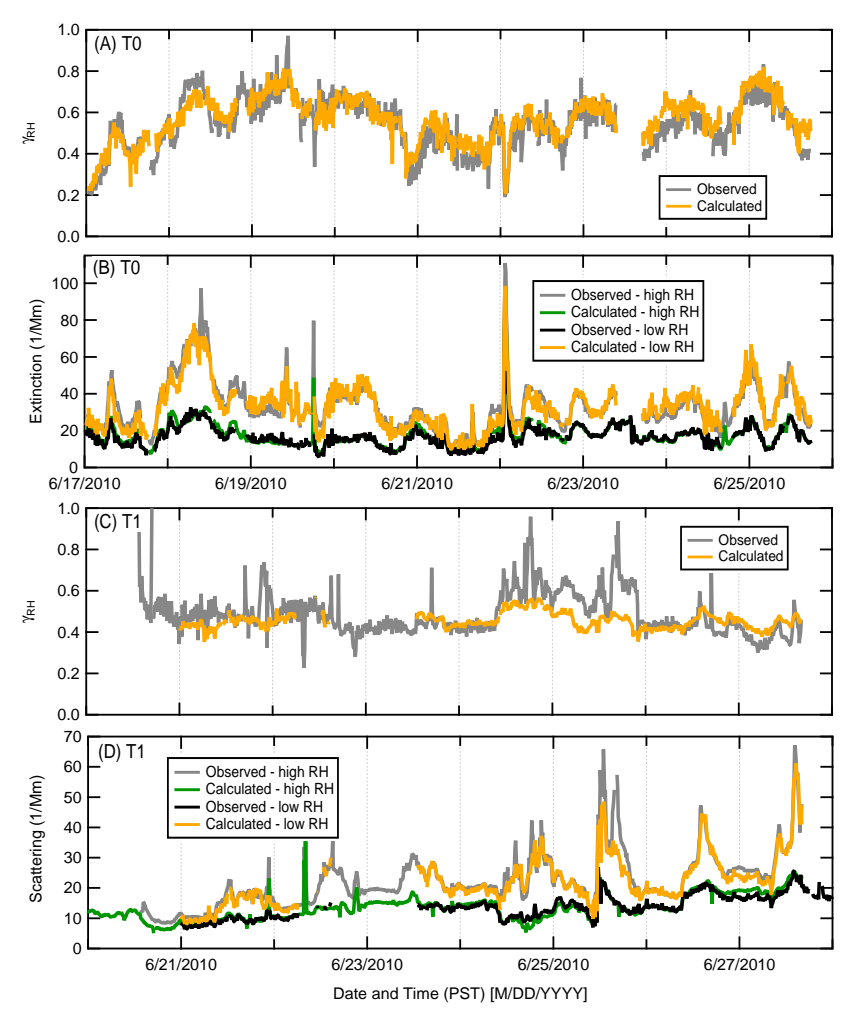

Figure 3. The time-series of the observed (gray) and calculated (orange) $\gamma_{\mathrm{RH}}$ values at T0 (a) and T1 (c). The observed and calculated optical properties, $b_{\text {ext }}$ or $b_{\text {sca }}$, for the lowest (green and black, respectively) and highest (grey and gold, respectively) RH channels for the CRD at T0 (b) and humidigraph at T1 (d). The calculated traces are produced by the optical hygroscopicity model described in the main text.

tion is thought to have homogenized the particle composition between the two sites (Fast et al., 2012; Zaveri et al., 2012).

\subsection{Optical property model/measurement comparison}

\subsubsection{Optical closure under low-humidity conditions}

Time-series of $b_{\text {ext,low }}$ and $b_{\text {sca,low }}$ for $\mathrm{PM}_{2.5}$ and $\mathrm{PM}_{1}$ have been calculated from Mie theory, with the $\mathrm{PM}_{2.5}$ results shown in Fig. 3. There is generally good agreement between the measured and calculated $b_{\text {ext,low }}$ or $b_{\text {sca,low }}$ (Fig. $4 \mathrm{a}$ and b) at both sites. The slope of a linear orthogonal distance regression (ODR) fit of the observed vs. calculated $b_{\text {ext,low }}$ at T0 is $1.005( \pm 0.005)(1 \sigma$ of the fit $)$ and for the $b_{\text {sca,low }}$ at $\mathrm{T} 1$ is $1.02( \pm 0.004)$, which demonstrates agreement and closure to well within the experimental uncertainties. (Note that for T0, only data from the period prior to 6/22 at 21:00 PST, when the APS was in operation, are included in the fit.) The generally good agreement at $\mathrm{T} 1$ is notable since no explicit size cut was used during sampling and is important in the context of the particle hygroscopicity assessment discussed below. For these fits (Fig. 4a and 4b), the $y$ intercept was 

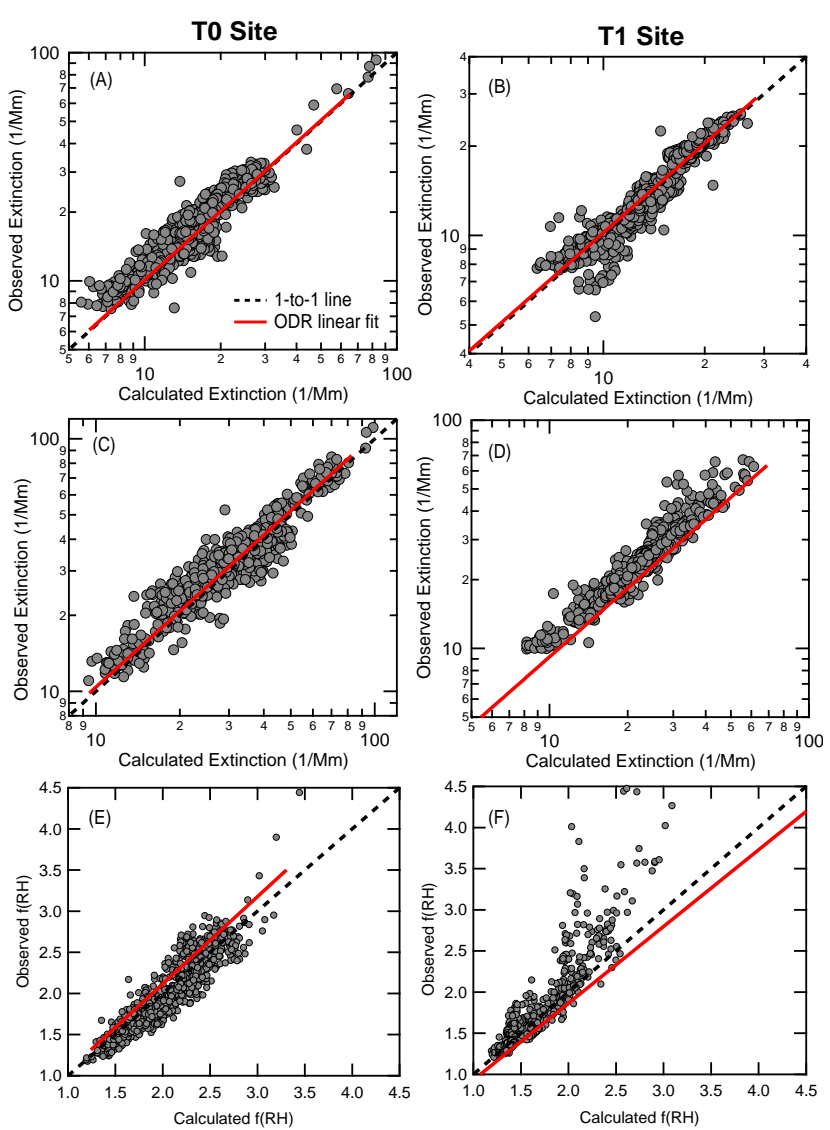

Figure 4. Scatter plot comparisons between observed and calculated $b_{\text {ext }}$ or $b_{\text {scat }}$ for low RH (a and b) and high RH (c and d) and $f(\mathrm{RH})$ (e and $\mathbf{f}$ ) values at the T0 site (left panels) and the T1 site (right panels). The red and dashed lines represent the best ODR linear fit to the data and the 1:1 line, respectively. For T0, calculated $b_{\text {ext,low }}$ and $b_{\text {ext,high values are excluded during the period }}$ over which synthetic supermicron size distributions were used.

constrained to be equal to zero, but the intercepts produced when the fits were not forced through zero were statistically indistinguishable from zero at the $95 \%$ confidence level.

The calculated average supermicron fractional contribution $\left(f_{\text {super }}\right)$ to the $\mathrm{PM}_{2.5} b_{\text {ext }}$ at $\mathrm{T} 0$ ranged from 0.05 to 0.4 , with a mean value of $0.21 \pm 0.10(1 \sigma)$, while at $\mathrm{T} 1 f_{\text {super }}$ ranged from 0.05 to 0.6 with a mean value of $0.22 \pm 0.13$ $(1 \sigma)$ (Fig. S3). The $f_{\text {super }}$ at $\mathrm{T} 1$ after 21 June (i.e., during the period when reliable high RH measurements are available) were smaller, varying from 0.05 to 0.4 with a mean of $0.11 \pm 0.05(1 \sigma)$ (Fig. S3). There is a general correspondence between periods of high supermicron influence at $\mathrm{T} 0$ and T1, in particular during the period from 18 to 21 June, although the $f_{\text {super }}$ values at $\mathrm{T} 1$ tend to lag those at $\mathrm{T} 0$ by $6-12 \mathrm{~h}$.

\subsubsection{Optical closure under elevated-humidity conditions}

The calculation of wet particle optical properties requires that the GFs (or equivalently $\kappa$ values) for the major PM components are known so that the water uptake due to each component can be assessed. The $\kappa$ values for the major highly hygroscopic inorganic components, ammonium nitrate and ammonium sulfate, are known, and BC and HOA are essentially non-hygroscopic, with $\kappa$ values of 0 and 0.006 , respectively (Table 1; Petters and Kreidenweis, 2007). In contrast, the hygroscopicity of OOA is variable and depends on the specific OOA composition, with reported $\kappa_{\mathrm{OOA}}$ values from field observations or $\kappa$ values for oxidized OA from laboratory experiments ranging from $\sim 0.05-0.25$ (Cappa et al., 2011; Jimenez et al., 2009; Lambe et al., 2011; Levin et al., 2014; Massoli et al., 2010; Mei et al., 2013). The hygroscopicity of the supermicron particles in this study, $\kappa_{\text {super }}$, is also not a priori well-established. Since water uptake can have a large impact on the optical properties of ambient PM, it is important that the hygroscopicity of the various contributing components be well understood.

Average optimal values for $\kappa_{\mathrm{OOA}}$ and $\kappa_{\text {super }}$ for both the T0 and $\mathrm{T} 1$ sites have been established for this data set by determining the specific values that lead to the best agreement between the calculated and observed $\gamma$ time-series. Since there are two unknowns, we have taken the simplifying approach of assuming that $\kappa_{\mathrm{OOA}}$ and $\kappa_{\text {super }}$ are site-specific constants for the entire campaign. Limitations of this simplification are examined further below. Optimal $\kappa_{\mathrm{OOA}}$ and $\kappa_{\text {super }}$ are determined by independently varying them over reasonable ranges until the best model/measurement agreement is obtained, as characterized by minimization of a parameter similar to $\chi^{2}$, here calculated as

$\chi^{2}=\sum_{t} \frac{\left(\gamma_{\mathrm{obs}, \mathrm{t}}-\gamma_{\mathrm{calc}, \mathrm{t}}\right)^{2}}{\left(\gamma_{\mathrm{obs}, \mathrm{t}}+\gamma_{\mathrm{calc}, \mathrm{t}}\right) / 2}$.

Results from the optimization procedure are illustrated in Fig. 5, which shows color maps of the calculated $\chi^{2}$ values as a function of $\kappa_{\mathrm{OOA}}$ and $\kappa_{\mathrm{super}}$ for the two sites. For each site a single global minimum $\chi^{2}$ value is obtained. Absolute values and associated uncertainties in the derived values are discussed further below.

Time-series of the optimized $b_{\text {ext,high }}$ and $b_{\text {sca,high }}$ and for $\gamma$ are shown for the periods 17-26 June at T0 and 21-28 June at T1 (Fig. 3), and the modeled extinction/scattering coefficients are compared to the measurements in Fig. $4 \mathrm{c}$ and d. (Time-series of the RH in the high $\mathrm{RH}$ channels, and the associated $f(\mathrm{RH})$ are shown in Fig. S4.) The overall model/measurement agreement in the calculated extensive optical properties is good, with slopes of $0.992( \pm 0.004)(1 \sigma$ of the fit) at T0 and $1.03( \pm 0.004)$ at T1. This good agreement is as expected given the model/measurement agreement under low RH conditions and the fact that the $\kappa_{\mathrm{OOA}}$ and $\kappa_{\text {super }}$ were optimized to give good model/measurement in $\gamma$. 

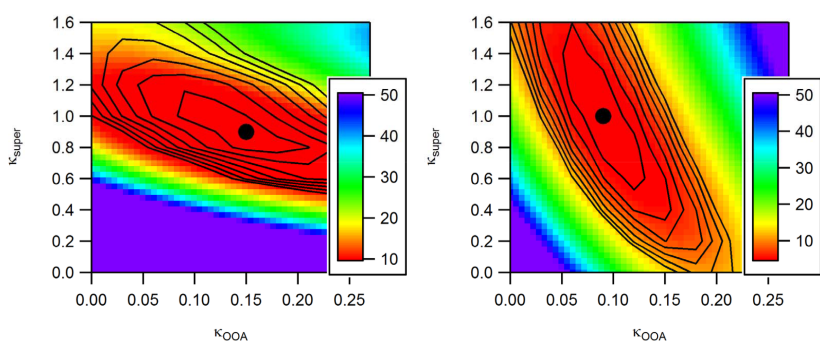

Figure 5. Visualization of the optimization procedure for the supermicron and OOA hygroscopicities at T0 (left) and T1 (right). The $\chi^{2}$ value is shown as a false color image where the redder colors are lower in value. The global minimum is indicated by the dot and contours are included added to accentuate the shape of the surface.

\subsubsection{Oxygenated organic aerosol hygroscopicity}

The optimal average OOA hygroscopicities are $\kappa_{\mathrm{OOA}}=0.15 \pm 0.04$ for $\mathrm{T} 0$ and $0.09 \pm 0.03$ for $\mathrm{T} 1$. The uncertainty estimate is discussed in Sect. 5.2.5. There is some cross-sensitivity to the optimization results; e.g., larger values of $\kappa_{\text {super }}$ lead to smaller values of $\kappa_{\mathrm{OOA}}$, and vice versa. However, the particular cross-sensitivities of $\kappa_{\text {super }}$ and $\kappa_{\mathrm{OOA}}$ differ between the two sites. At T0, the optimal $\kappa_{\text {super }}$ exhibits relatively small sensitivity to the $\kappa_{\mathrm{OOA}}$, while the reverse is not true. At T1, the optimal $\kappa_{\text {super }}$ exhibits greater sensitivity to variations in the $\kappa_{\mathrm{OOA}}$, with the $\kappa_{\mathrm{OOA}}$ reasonably independent of $\kappa_{\text {super }}$. These differences in cross-sensitivity between the two sites arise from differences in particle composition and the relative contributions of sub- and supermicron particles to the total extinction or scattering. At $\mathrm{T} 0$, the supermicron contribution to total extinction is substantial, while at T1 it is relatively small over the period considered. At T1, the overall scattering is dominated by OOA, while at T0 the OOA contribution, although not insignificant, is comparably smaller.

The consistency of the derived $\kappa_{\mathrm{OOA}}$ between the two sites suggests that for OOA in the Sacramento region in the summer $\kappa_{\mathrm{OOA}} \sim 0.09-0.15$, although the optimal $\kappa_{\mathrm{OOA}}$ derived for $\mathrm{T} 1$ is likely more robust than that at $\mathrm{T} 0$ because of the greater sensitivity of $\kappa_{\mathrm{OOA}}$ to $\kappa_{\text {super }}$ at T0. The oxygento-carbon atomic ratio $(\mathrm{O}: \mathrm{C})$ for $\mathrm{OOA}$ at $\mathrm{T} 1$ was $\sim 0.5$ (Setyan et al., 2012), and although comparable values are unavailable for the T0 site, the aircraft measurements indicated O : C for OOA is $\sim 0.6$ over the Sacramento region in general (Shilling et al., 2013). Previous work suggests that there is some relationship between degree of oxygenation of OA and $\kappa$. The observed $\kappa_{\mathrm{OOA}}$ and OOA O : C are consistent with $\kappa_{\mathrm{OA}} / \mathrm{O}: \mathrm{C}$ relationships determined from laboratory measurements (Jimenez et al., 2009; Lambe et al., 2011; Massoli et al., 2010) and as derived from other field observations (Chang et al., 2010; Jimenez et al., 2009; Mei et al., 2013). Altogether, this suggests that the assumption of a time-invariant, albeit site-specific $\kappa_{\mathrm{OOA}}$ during CARES is reasonable, and our derived values fall within the expected range. The small difference in OOA hygroscopicities between the two sites ( 0.15 vs. 0.09 ) may be due to the addition of relatively less oxidized OA produced from the biogenic precursors encountered during transit from $\mathrm{T} 0$ to $\mathrm{T} 1$, with decreased production from anthropogenically precursors as the urban plume dilutes and spreads. Alternatively, it could indicate that $\kappa_{\mathrm{HOA}}$ is somewhat underestimated at T0. (There were two less oxygenated OA factors observed at $\mathrm{T} 0$, which were combined into a single HOA factor because they exhibited generally similar temporal dependencies. However, the average mass spectrum for one of these factors suggested a potential cooking source and appeared to be somewhat more oxidized than OA from vehicle emissions. More detailed analysis of the PMF results from T0 is beyond the scope of the current study.)

\subsubsection{Supermicron particle hygroscopicity}

The optimal campaign-average $\kappa_{\text {super }}$ values were $0.9 \pm 0.2$ at $\mathrm{T} 0$ and $1.0 \pm 0.2$ at $\mathrm{T} 1$ (uncertainties discussed in Sect. 5.2.5). These are between the values for the major submicron inorganic species $\left(\left(\mathrm{NH}_{4}\right)_{2} \mathrm{SO}_{4}\right.$ and $\left.\mathrm{NH}_{4} \mathrm{NO}_{3}\right)$ and the major component of sea salt, $\mathrm{NaCl}$ (Table 1). (The $\kappa$ for $\mathrm{NaCl}$ is $\sim 1.2$; Petters and Kreidenweis, 2007.) Such large values for $\kappa_{\text {super }}$ indicate that the supermicron particles during CARES were overall quite hygroscopic. The SPLAT II and PALMS measurements indicate that a substantial fraction of the supermicron particles contained $\mathrm{NaCl}$ and other hygroscopic salts (Fig. 6), indicative of a marine sea-spray influence and generally consistent with the large $\kappa_{\text {super }}$ values.

The average $\kappa_{\text {super }}$ values were determined assuming that the supermicron particle hygroscopicity was constant in time at each site. However, the single particle mass spectrometry results indicate that there are some variations in the supermicron particle composition, which could lead to temporal variations in $\kappa_{\text {super }}$. The potential variability in $\kappa_{\text {super }}$ has been assessed by minimizing the difference between the modeled and measured $\gamma_{\mathrm{ext}}$ and $\gamma_{\mathrm{sca}}$ at every point in time while holding $\kappa_{\mathrm{OOA}}$ constant at 0.15 , as opposed to a single campaign average value. A histogram of the derived individ-

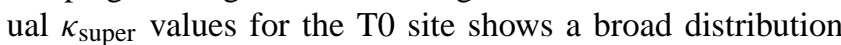
centered around 0.8 (Fig. S5). (The T0 site was considered here since the supermicron contribution to scattering at this site was larger. Also, use of a different $\kappa_{\mathrm{OOA}}$ would shift the distribution, but have minimal influence on the spread.) Assessing variability in $\kappa_{\text {super }}$ by setting $\kappa_{\mathrm{OOA}}$ to be constant is reasonable given the similarity between the $\kappa_{\mathrm{OOA}}$ values at $\mathrm{T} 0$ and $\mathrm{T} 1$ and with literature values.

Variability in the supermicron composition could result from variations in sources of primary supermicron PM or from photochemical processing. Sacramento is located about 90 miles from the San Francisco Bay and Pacific Ocean; thus, sea-spray particles transported to the T0 site in Sacramento 


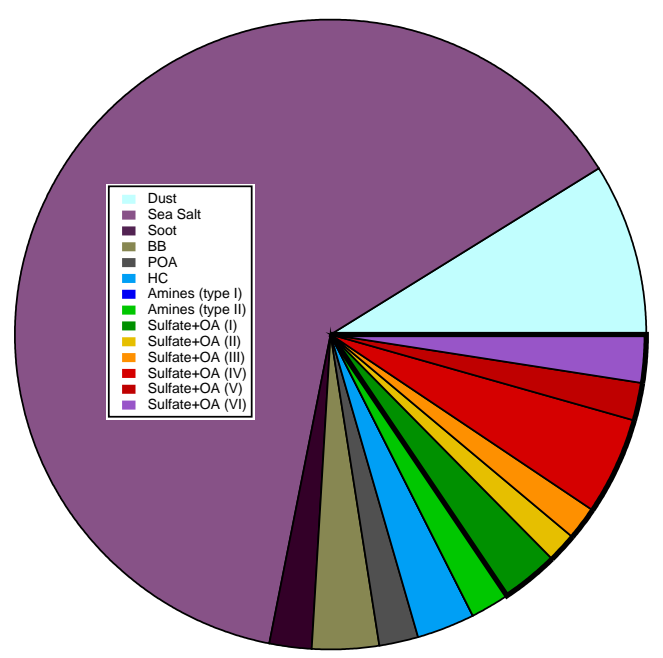

Figure 6. Fraction of total sampled number of supermicron particles at T0, as identified by the SPLAT II instrument, over the period 17 June-25 June. It should be noted that the sea-salt particle type, which is the most abundant particle type observed, includes particles with varying amounts of $\mathrm{NaCl}, \mathrm{NaNO}_{3}$, and organics. The solid black outline groups the various Sulfate + OA particle types. (Amine Type I particles were not observed in sufficient abundance to be seen in the pie chart.)

and the T1 site in the Sierra Foothills will likely have undergone some photochemical processing along the way. As noted above, sea-salt-containing particles make up a substantial proportion of supermicron particles sampled during the measurement period (Fig. 6). The majority of the sea-salt particles observed were processed to differing extents as indicated in the single particle mass spectra by the presence of characteristic peaks for $\mathrm{NaCl}(m / z, 23,81,83)$ and $\mathrm{NaNO}_{3}$ $(\mathrm{m} / \mathrm{z} 23,62,30,39,78,92,108)$ with different relative intensities. Displacement of chloride with nitrate as a result of $\mathrm{HNO}_{3}$ uptake on sea-salt-containing particles (Gard et al., 1998) would lead to a decrease in the overall particle hygroscopicity since $\kappa_{\mathrm{NaNO}_{3}} \sim 0.84<\kappa_{\mathrm{NaCl}} \sim 1.2$ (Petters and Kreidenweis, 2007). Similarly, the addition of secondary organic material would lead to a decrease in $\kappa$ relative to that for fresh sea salt, since $\kappa_{\mathrm{OOA}}<\kappa_{\mathrm{NaNO}_{3}}<\kappa_{\mathrm{NaCl}}$. Thus, although classified simply as "sea salt", more detailed consideration of the mass spectra associated with these sodiumcontaining particles indicate compositional variations associated with photochemical processing, with both nitrate and organic signatures observed.

An example of the dependence of $\kappa_{\text {super }}$ on particle composition is shown for the $\mathrm{T} 1$ site based on single particle mass spectra from the PALMS instrument for 15 June, a day during which the supermicron fraction of scattering was particularly large $(0.37 \pm 0.03)$. On this day there is an evolution from sea-salt-containing particles with predominately chloride ion signatures (at 9:30 a.m. LT) to mixed chloride-nitrate-organic (at 1:15 p.m.) to mostly organic ( $\sim$ p.m.) (Fig. 7 ). The de-

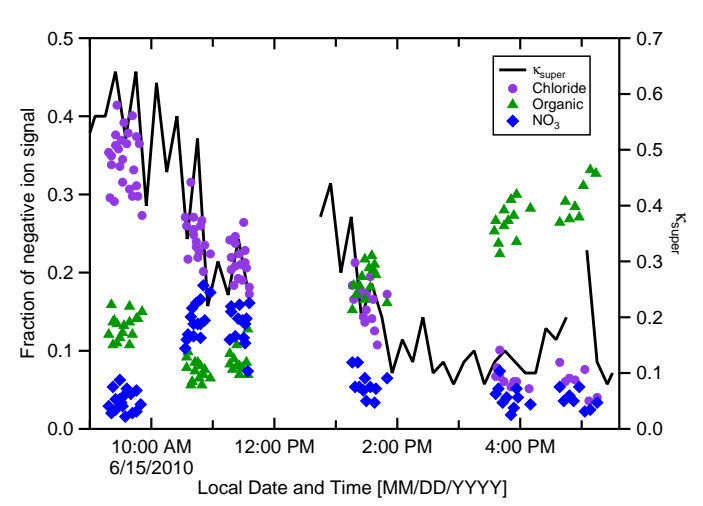

Figure 7. Fractional contributions (left axis) of chloride (purple), organics (green) and nitrates (blue) in the PALMS single particle negative ion mass spectra for sea-salt-containing particles, identified by sodium in the positive ion spectra, and (right axis) the derived supermicron hygroscopicity parameter, $\kappa_{\text {super }}$. The ion fractions do not add up to unity due to contributions from other ion peaks not included here.

rived $\kappa_{\text {super }}$ is not constant, and there is a strong correspondence between the measured chloride fraction of sea-saltderived particles and $\kappa_{\text {super }}$, with smaller $\kappa_{\text {super }}$ associated with smaller chloride fractions. As far as we are aware, this is the first direct demonstration of the influence of photochemical processing on the hygroscopicity of supermicron particles.

In addition to chemical processing affecting particle hygroscopicity, variations in the sources of emitted primary supermicron particles can influence the observed supermicron hygroscopicity. For example, non-sea-salt-containing particles can be emitted as sea spray in addition to sea-salt (i.e., sodium-containing) particles (Facchini et al., 2008; Prather et al., 2013; Quinn et al., 2014), which may have lower hygroscopicity than sea salt. Further, there are also supermicron dust particles, the hygroscopicity of which can be quite variable but is typically lower than sea salt (Koehler et al., 2009; Zhang et al., 2014). Finally, sulfate + OA particles also contribute to the supermicron particle burden (Fig. 6). Temporal variations in the contributions from these different sources, as well as variations in the extent of photochemical processing, will all contribute to the observed variability in the $\kappa_{\text {super }}$ values at both sites. Variability in supermicron composition and the consequent impacts on the overall particle hygroscopicity will clearly require further study, ideally with both quantitative bulk and single-particle chemical information as constraints.

\subsubsection{Sensitivity/uncertainty analysis}

The sensitivity of the retrieved values of $\kappa_{\mathrm{OOA}}$ and $\kappa_{\text {super }}$ to the assumed $\kappa$ values of the other components (e.g., $\left(\mathrm{NH}_{4}\right) \mathrm{NO}_{3},\left(\mathrm{NH}_{4}\right)_{2} \mathrm{SO}_{4}, \mathrm{HOA}$, and $\left.\mathrm{BC}\right)$ has been investigated. Although the $\kappa$ values of these other components have 
Table 2. Change in absolute model retrieved $\kappa_{\mathrm{OOA}}$ or $\kappa_{\text {super }}$ for a given perturbation in the assumed hygroscopicities for other particle components $\left(\kappa_{\text {other }}\right.$ ), along with sensitivities shown as $\Delta \kappa_{\mathrm{OOA}} / \Delta \kappa_{\mathrm{other}}$ and $\Delta \kappa_{\text {super }} / \Delta \kappa_{\text {other }}$

\begin{tabular}{|c|c|c|c|c|c|c|c|c|c|}
\hline \multirow[t]{2}{*}{ Component } & \multirow{2}{*}{$\begin{array}{l}\Delta \kappa_{\text {other }} \\
(\% \text { and absolute })\end{array}$} & \multicolumn{4}{|c|}{ T0 } & \multicolumn{4}{|c|}{$\mathrm{T} 1$} \\
\hline & & $\Delta \kappa_{\mathrm{OOA}}$ & $\Delta \kappa_{\mathrm{OOA}} / \Delta \kappa_{\text {other }}$ & $\Delta \kappa_{\text {super }}$ & $\Delta \kappa_{\text {super }} / \Delta \kappa_{\text {other }}$ & $\Delta \kappa_{\mathrm{OOA}}$ & $\Delta \kappa_{\mathrm{OOA}} / \Delta \kappa_{\mathrm{other}}$ & $\Delta \kappa_{\text {super }}$ & $\Delta \kappa_{\text {super }} / \Delta \kappa_{\text {other }}$ \\
\hline \multirow{2}{*}{$\left(\mathrm{NH}_{4}\right)_{2} \mathrm{SO}_{4}$} & $-10 \%(-0.067)$ & 0.0077 & -0.12 & 0.0077 & -0.12 & 0.0023 & -0.034 & 0.192 & -2.86 \\
\hline & $+10 \%(+0.067)$ & -0.0075 & -0.11 & -0.0091 & -0.14 & -0.0070 & -0.104 & -0.069 & -1.03 \\
\hline \multirow[t]{2}{*}{$\mathrm{NH}_{4} \mathrm{NO}_{3}$} & $-10 \%(-0.067)$ & 0.0044 & -0.065 & 0.0011 & -0.016 & 0.0014 & -0.024 & 0.0061 & -0.091 \\
\hline & $+10 \%(0.067)$ & -0.0044 & -0.065 & -0.0014 & -0.021 & -0.0018 & & -0.0053 & -0.079 \\
\hline \multirow[t]{2}{*}{$\mathrm{BC}$} & $\mathrm{n} / \mathrm{a}(0.02)$ & -0.0015 & -0.075 & 0.0007 & 0.035 & -0.0004 & -0.021 & -0.0019 & -0.095 \\
\hline & $\mathrm{n} / \mathrm{a}(0.05)$ & -0.0038 & -0.076 & 0.0021 & 0.042 & 0.00045 & 0.009 & -0.0135 & -0.27 \\
\hline \multirow[t]{2}{*}{ Chloride } & $-10 \%(-0.12)$ & 0.0004 & -0.003 & 0.0005 & -0.004 & $-6 \times 10^{-6}$ & $-5 \times 10^{-5}$ & -0.0003 & -0.0025 \\
\hline & $+7 \%(0.08)$ & 0.0004 & 0.005 & -0.0005 & -0.006 & -0.0002 & -0.0025 & -0.0011 & 0.0137 \\
\hline \multirow[t]{2}{*}{ HOA } & $+200 \%(0.02)$ & -0.0052 & -0.260 & $-3 \times 10^{-6}$ & -0.0002 & & & & \\
\hline & $+733 \%(0.05)$ & -0.0167 & -0.334 & -0.0001 & -0.002 & & & & \\
\hline \multirow[t]{2}{*}{ HOA } & $+67 \%(0.01)$ & & & & & -0.0004 & -0.040 & -0.0017 & -0.170 \\
\hline & $+367 \%(0.028)$ & & & & & -0.0018 & -0.064 & -0.0032 & -0.114 \\
\hline
\end{tabular}

been previously established, they still contain some uncertainty. The sensitivity of $\kappa_{\mathrm{OOA}}$ and $\kappa_{\text {super }}$ have been determined by perturbing the other species $\kappa$ values by some amount and then recalculating optimized $\kappa_{\mathrm{OOA}}$ and $\kappa_{\text {super }}$ values. For more hygroscopic components (ammonium sulfate and nitrate and sodium chloride) the $\kappa$ values were varied by $\pm 10 \%$ around the literature values. The values for $\mathrm{BC}$ and HOA, which are assumed to be essentially non-hygroscopic, were both increased substantially from their literature values of $\kappa_{\mathrm{BC}}=0$ and $\kappa_{\mathrm{HOA}}=0.006$ (to 0.02 and 0.05 for $\mathrm{BC}$ and by up to 0.05 for HOA at T0, where the loadings were higher and the greatest effect was thought to be likely). Sensitivities were determined by perturbing one component at a time. In general, an increase in $\kappa$ for one of the other species resulted in a lowering of both $\kappa_{\mathrm{OOA}}$ and $\kappa_{\text {super }}$, and vice versa, as expected since volume additivity is assumed. The absolute and relative changes in $\kappa_{\mathrm{OOA}}$ and $\kappa_{\text {super }}$ for a given change in $\kappa$ of the other species have been quantified (Table 2).

For T0, the $\kappa_{\mathrm{OOA}}$ is particularly sensitive to changes in $\kappa_{\mathrm{HOA}}$, whereas the $\kappa_{\text {super }}$ is most sensitive to changes in $\kappa_{\mathrm{AS}}$. The sensitivity of $\kappa_{\mathrm{OOA}}$ to $\kappa_{\mathrm{HOA}}$ comes about because the relative concentration of HOA was substantial at T0 and was sometimes correlated with OOA, while the sensitivity of $\kappa_{\text {super }}$ to $\kappa_{\mathrm{AS}}$ comes about because $\kappa_{\mathrm{AS}}$ is similar in magnitude to the derived $\kappa_{\text {super }}$. Despite these sensitivities, the overall sensitivity-based uncertainty of the $\kappa_{\mathrm{OOA}}$ deriving from uncertainties in the $\kappa$ values of the other species at T0 is relatively small, estimated as $\pm 7 \%$ from summing the errors in quadrature. The sensitivity-based uncertainty in the $\kappa_{\text {super }}$ deriving from uncertainties in the other $\kappa$ values is similarly small, estimated as $\pm 5 \%$. The overall uncertainty in $\kappa_{\mathrm{OOA}}$ and $\kappa_{\text {super }}$ also depends on the anti-correlation between these two parameters (Fig. 4) and in the RH measurement $( \pm 2 \%)$. The uncertainty in $\mathrm{RH}$ gives an additional uncertainty in $\kappa_{\mathrm{OOA}}$ of \pm 0.02 and in $\kappa_{\text {super }}$ of \pm 0.11 . The uncertainty in $\kappa_{\mathrm{OOA}}$ and $\kappa_{\text {super }}$ at $\mathrm{T} 0$ from their cross-sensitivities are es- timated as \pm 0.03 and \pm 0.15 , respectively, based on the $\chi^{2}$ values (Fig. 5). Thus, for T0, the mean values for the OOA and supermicron hygroscopicity are $\kappa_{\mathrm{OOA}}=0.15 \pm 0.04$ and $\kappa_{\text {super }}=0.9 \pm 0.2$.

At $\mathrm{T} 1$, because $b_{\text {ext }}$ was dominated by $\mathrm{OA}$, and specifically OOA, the derived $\kappa_{\mathrm{OOA}}$ values are much less sensitive to variations in $\kappa$ for other species, meaning that the overall uncertainty for $\kappa_{\mathrm{OOA}}$ at $\mathrm{T} 1$ is determined predominately by the RH uncertainty. The supermicron contribution to $b_{\text {ext }}$ at T1 is comparably small, making $\kappa_{\text {super }}$ much more sensitive to variations in the other $\kappa$ values compared to T0. Specifically, $\kappa_{\text {super }}$ is highly dependent on the $\kappa_{\mathrm{AS}}$, changing by 0.12 for a $10 \%$ change in $\kappa_{\mathrm{AS}}$. The estimated uncertainty in $\kappa_{\text {super }}$ from the cross-sensitivity to $\kappa_{\mathrm{OOA}}$ is 0.1 . Thus, for $\mathrm{T} 1$, the mean values for the OOA and supermicron hygroscopicity are $\kappa_{\mathrm{OOA}}=0.09 \pm 0.03$ and $\kappa_{\text {super }}=1.0 \pm 0.2$.

\subsubsection{Influence of assumed mixing state}

Three different models of the submicron particle mixing state were tested in calculating the particle optical properties: an internal mixture with size-dependent composition (the base case discussed above), an internal mixture with sizeindependent composition and an external mixture with sizedependent composition. The optimization procedure was repeated for the two alternative models. The derived optimal $\kappa_{\mathrm{OOA}}$ values are $0.15,0.13$, and 0.10 for $\mathrm{T} 0$ and 0.09 , 0.16 and 0.08 for $\mathrm{T} 1$ for the internal + size-dependent composition, internal + size-independent composition and external mixture models, respectively. It is apparent that the derived $\kappa_{\mathrm{OOA}}$ exhibits some, albeit limited sensitivity to the assumed mixing state, at least for the particle distributions in the Sacramento region in the summer. The derived opti-

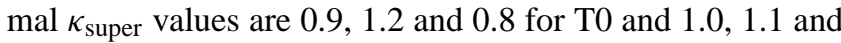
0.9 for $\mathrm{T} 1$ for the internal + size-dependent, internal + sizeindependent and external mixture models, respectively. Like $\kappa_{\mathrm{OOA}}$, the derived $\kappa_{\text {super }}$ is not strongly dependent upon the 
model formulation, although because the supermicron particles are treated as a separate, internally mixed mode in all cases this is perhaps to be expected. Despite the similarity of the derived $\kappa_{\mathrm{OOA}}$ and $\kappa_{\text {super }}$ values between the three models, the two size-dependent composition models generally resulted in more definitive retrievals of the hygroscopicities; i.e., the calculated $\chi^{2}$ values exhibited a more well-defined minimum. This suggests that accounting for differences in the size distributions of inorganic and organic components may be important for accurate calculation of the optical properties of ambient PM at elevated RH.

\subsubsection{Influence of particulate light absorption}

In the Mie calculations presented herein, it was assumed that the particles were non-absorbing, and thus that $b_{\text {ext }}=b_{\text {sca }}$. However, black carbon is highly absorbing in the visible wavelength range, and although the time-series shown in Fig. 1 demonstrates that BC is typically only a small fraction of the total submicron PM, it is important to consider the extent to which the results above might change if light absorption by $\mathrm{BC}$ is included. One of the challenges in the simulation of $\mathrm{BC}$ light absorption is properly accounting for the influence of internal mixing (i.e., the presence of coatings) on the light absorption by BC. In theory (Bond et al., 2006; Fuller et al., 1999) and in some laboratory experiments (e.g., Cappa et al., 2012; Schnaiter et al., 2005), nonabsorbing coatings lead to an enhancement in the absorption by $\mathrm{BC}$ particles above that of uncoated (externally mixed) $\mathrm{BC}$ particles. However, measurements for dry ambient particles during CARES indicated absorption enhancements that were substantially smaller than expected (Cappa et al., 2012). For the humidified aerosols, the effects of water on $\mathrm{BC}$ absorption enhancements for ambient particles remain ill characterized, although there is some experimental evidence to suggest that water uptake can lead to enhancement of absorption (Mikhailov et al., 2006).

The magnitude of the potential influence of light absorption on the calculated hygroscopic growth has been assessed through a series of test calculations. Results are compared between calculations for particles that were assumed to have an overall dry diameter of $300 \mathrm{~nm}$, but where (i) the particles are well-mixed and non-absorbing, (ii) the particles are well-mixed and the $\mathrm{BC}$ fraction is absorbing and (iii) the $\mathrm{BC}$ exists as an absorbing core with a non-absorbing coating, i.e., in a core-shell morphology. The dry particles are assumed to have $5 \%$ by volume BC, $20 \%$ ammonium sulfate and $75 \%$ OOA, giving a composite $\kappa_{\text {tot }}=0.25$ or a $\mathrm{GF}(85 \%)=1.33$. For the core-shell case, this corresponds to a $\mathrm{BC}$ core diameter of $110 \mathrm{~nm}$. The imaginary refractive index for $\mathrm{BC}$ is taken as 0.8 . The calculated $\gamma_{\text {ext }}$ for the three cases are $0.43,0.39$ and 0.41 , respectively. The calculated $\gamma_{\mathrm{sca}}$ for the three cases are $0.43,0.46$ and 0.48 , respectively. These test calculations indicate that the neglect of absorption by $\mathrm{BC}$ will have had a minimal influence on the $\gamma_{\text {ext }}$ calculations, and consequently on the derived $\kappa_{\mathrm{OOA}}$ and $\kappa_{\text {super }}$ at the T0 site. In contrast, the calculated $\gamma_{\text {sca }}$ without absorption might be biased low by a small amount, which could consequently lead to small low biases in the calculated $\kappa_{\mathrm{OOA}}$ and $\kappa_{\text {super }}$ at the $\mathrm{T} 1$ site.

\section{Conclusions}

Measurements of light extinction and light scattering by ambient particles $\left(\mathrm{PM}_{2.5}\right)$ were made at two sites under low and high RH conditions during the 2010 CARES campaign in Sacramento, CA to assess the influence of water uptake on the optical properties of the particles. The overall effect of water uptake on extinction and scattering was characterized by the optical hygroscopicity parameter $\gamma$. Concurrent measurements of particle composition allowed for assessment of the relationship between particle composition and the water uptake. Optical closure calculations for the low RH measurements indicate good model/measurement agreement when the model is constrained by observed size distributions. Effective hygroscopicities, i.e., $\kappa$ values, were determined for OOA and for supermicron (defined here as particles with $1 \mu \mathrm{m}<d_{\mathrm{p}, \mathrm{a}}<2.5 \mu \mathrm{m}$ ) particles based on comparison between observed and calculated $\gamma$ values. The derived campaign-average $\kappa_{\mathrm{OOA}}$ values at the two sites were similar, with $\kappa_{\mathrm{OOA}}=0.15 \pm 0.04$ (T0) and $0.09 \pm 0.03$ (T1), indicating that OOA is moderately hygroscopic, consistent with previous studies. The derived campaign-average $\kappa_{\text {super }}$ values at the two sites were also similar to each other, with $\kappa_{\text {super }}=0.9 \pm 0.2(\mathrm{~T} 0)$ and $1.0 \pm 0.2(\mathrm{~T} 1)$, indicating that the supermicron particles in this region were overall highly hygroscopic. However, the $\kappa_{\text {super }}$ exhibited some dependence on the particle composition, with larger values observed when the supermicron particles were dominated by sea salt and smaller values observed as chloride was replaced by nitrate or when supermicron organics were prevalent.

\section{The Supplement related to this article is available online at doi:10.5194/acp-15-4045-2015-supplement.}

Acknowledgements. D. B. Atkinson, J. G. Radney, J. Lum, K. R. Kolesar, C. D. Cappa and Q. Zhang were supported by of the US Department of Energy (DOE) Office of Biological and Environmental Research (OBER), Atmospheric System Research (ASR) Program through Grants No. DE-SC0008937 and DE-FG02-11ER65293. A. Zelenyuk and M. S. Pekour were supported by ASR and the EMSL (Environmental Molecular Sciences Laboratory), a national scientific user facility sponsored by the DOE-OBER and located at Pacific Northwest National Laboratory. The authors thank R. Subramanian for use of the SP2 data. Additional funding for data collection at the ground sites (including of the SP2 data) was provided by the Atmospheric Radiation Measurement (ARM) Program of the DOE-OBER. 
Edited by: J. Thornton

\section{References}

Bohren, C. F. and Huffman, D. R.: Absorption and scattering of light by small particles, Wiley, New York, 1983.

Bond, T. C., Habib, G., and Bergstrom, R. W.: Limitations in the enhancement of visible light absorption due to mixing state, J. Geophys. Res.-Atmos., 111, D20211, doi:10.1029/2006JD007315, 2006.

Canagaratna, M. R., Jayne, J. T., Jimenez, J. L., Allan, J. D., Alfarra, M. R., Zhang, Q., Onasch, T. B., Drewnick, F., Coe, H., Middlebrook, A., Delia, A., Williams, L. R., Trimborn, A. M., Northway, M. J., DeCarlo, P. F., Kolb, C. E., Davidovits, P., and Worsnop, D. R.: Chemical and microphysical characterization of ambient aerosols with the Aerodyne aerosol mass spectrometer, Mass Spectrom. Rev., 26, 185-222, doi:10.1002/mas.20115, 2007.

Cappa, C. D., Che, D. L., Kessler, S. H., Kroll, J. H., and Wilson, K. R.: Variations in organic aerosol optical and hygroscopic properties upon heterogeneous OH oxidation, J. Geophys. Res.-Atmos., 116, D15204, doi:10.1029/2011jd015918, 2011.

Cappa, C. D., Onasch, T. B., Massoli, P., Worsnop, D., Bates, T. S., Cross, E., Davidovits, P., Hakala, J., Hayden, K., Jobson, B. T., Kolesar, K. R., Lack, D. A., Lerner, B., Li, S. M., Mellon, D., Nuaanman, I., Olfert, J., Petaja, T., Quinn, P. K., Song, C., Subramanian, R., Williams, E. J., and Zaveri, R. A.: Radiative absorption enhancements due to the mixing state of atmospheric black carbon, Science, 337, 1078-1081, doi:10.1126/science.1223447, 2012.

Cappa, C. D., Williams, E. J., Lack, D. A., Buffaloe, G. M., Coffman, D., Hayden, K. L., Herndon, S. C., Lerner, B. M., Li, S.M., Massoli, P., McLaren, R., Nuaaman, I., Onasch, T. B., and Quinn, P. K.: A case study into the measurement of ship emissions from plume intercepts of the NOAA ship Miller Freeman, Atmos. Chem. Phys., 14, 1337-1352, doi:10.5194/acp-14-13372014, 2014.

Carrico, C. M., Kus, P., Rood, M. J., Quinn, P. K., and Bates, T. S.: Mixtures of pollution, dust, sea salt, and volcanic aerosol during ACE-Asia: Radiative properties as a function of relative humidity, J. Geophys. Res.-Atmos., 108, 8650, doi:10.1029/2003JD003405, 2003.

Chang, R. Y.-W., Slowik, J. G., Shantz, N. C., Vlasenko, A., Liggio, J., Sjostedt, S. J., Leaitch, W. R., and Abbatt, J. P. D.: The hygroscopicity parameter $(\kappa)$ of ambient organic aerosol at a field site subject to biogenic and anthropogenic influences: relationship to degree of aerosol oxidation, Atmos. Chem. Phys., 10, 5047-5064, doi:10.5194/acp-10-5047-2010, 2010.

Cziczo, D. J., Thomson, D. S., Thompson, T. L., DeMott, P. J., and Murphy, D. M.: Particle analysis by laser mass spectrometry (PALMS) studies of ice nuclei and other low number density particles, Int. J. Mass Spectrom., 258, 21-29, doi:10.1016/j.ijms.2006.05.013, 2006.

DeCarlo, P. F., Slowik, J. G., Worsnop, D., Davidovits, P., and Jimenez, J. L.: Particle morphology and density characterization by combined mobility and aerodynamic diameter measure- ments. Part 1: Theory, Aerosol Sci. Technol., 38, 1185-1205, doi:10.1080/027868290903907, 2004.

DeCarlo, P. F., Kimmel, J. R., Trimborn, A., Northway, M. J., Jayne, J. T., Aiken, A. C., Gonin, M., Fuhrer, K., Horvath, T., Docherty, K. S., Worsnop, D. R., and Jimenez, J. L.: Field-deployable, high-resolution, time-of-flight aerosol mass spectrometer, Anal. Chem., 78, 8281-8289, doi:10.1021/ac061249n, 2006.

Facchini, M. C., Rinaldi, M., Decesari, S., Carbone, C., Finessi, E., Mircea, M., Fuzzi, S., Ceburnis, D., Flanagan, R., Nilsson, E. D., de Leeuw, G., Martino, M., Woeltjen, J., and O’Dowd, C. D.: Primary submicron marine aerosol dominated by insoluble organic colloids and aggregates, Geophys. Res. Lett., 35, L17814, doi:10.1029/2008GL034210, 2008.

Fast, J. D., Gustafson Jr., W. I., Berg, L. K., Shaw, W. J., Pekour, M., Shrivastava, M., Barnard, J. C., Ferrare, R. A., Hostetler, C. A., Hair, J. A., Erickson, M., Jobson, B. T., Flowers, B., Dubey, M. K., Springston, S., Pierce, R. B., Dolislager, L., Pederson, J., and Zaveri, R. A.: Transport and mixing patterns over Central California during the carbonaceous aerosol and radiative effects study (CARES), Atmos. Chem. Phys., 12, 1759-1783, doi:10.5194/acp-12-1759-2012, 2012.

Fuller, K. A., Malm, W. C., and Kreidenweis, S. M.: Effects of mixing on extinction by carbonaceous particles, J. Geophys. Res. Atmos., 104, 15941-15954, doi:10.1029/1998jd100069, 1999.

Gard, E. E., Kleeman, M. J., Gross, D. S., Hughes, L. S., Allen, J. O., Morrical, B. D., Fergenson, D. P., Dienes, T., Gälli, M. E., Johnson, R. J., Cass, G. R., and Prather, K. A.: Direct Observation of Heterogeneous Chemistry in the Atmosphere, Science, 279, 1184-1187, doi:10.1126/science.279.5354.1184, 1998.

Haynes, W. M. and Lide, D. R.: CRC handbook of chemistry and physics : a ready-reference book of chemical and physical data, CRC Press, Boca Raton, FL, 2014.

Hegg, D. A., Covert, D. S., and Jonsson, H. H.: Measurements of size-resolved hygroscopicity in the California coastal zone, Atmos. Chem. Phys., 8, 7193-7203, doi:10.5194/acp-8-7193-2008, 2008.

IPCC: Climate Change 2013: The Physical Science Basis. Contribution of Working Group I to the Fifth Assessment Report of the Intergovernmental Panel on Climate Change, Cambridge University Press, Cambridge, UK and New York, NY, USA, 2013.

Jimenez, J. L., Canagaratna, M. R., Donahue, N. M., Prevot, A. S. H., Zhang, Q., Kroll, J. H., DeCarlo, P. F., Allan, J. D., Coe, H., Ng, N. L., Aiken, A. C., Docherty, K. S., Ulbrich, I. M., Grieshop, A. P., Robinson, A. L., Duplissy, J., Smith, J. D., Wilson, K. R., Lanz, V. A., Hueglin, C., Sun, Y. L., Tian, J., Laaksonen, A., Raatikainen, T., Rautiainen, J., Vaattovaara, P., Ehn, M., Kulmala, M., Tomlinson, J. M., Collins, D. R., Cubison, M. J., Dunlea, E. J., Huffman, J. A., Onasch, T. B., Alfarra, M. R., Williams, P. I., Bower, K., Kondo, Y., Schneider, J., Drewnick, F., Borrmann, S., Weimer, S., Demerjian, K., Salcedo, D., Cottrell, L., Griffin, R., Takami, A., Miyoshi, T., Hatakeyama, S., Shimono, A., Sun, J. Y., Zhang, Y. M., Dzepina, K., Kimmel, J. R., Sueper, D., Jayne, J. T., Herndon, S. C., Trimborn, A. M., Williams, L. R., Wood, E. C., Middlebrook, A. M., Kolb, C. E., Baltensperger, U., and Worsnop, D. R.: Evolution of organic aerosols in the atmosphere, Science, 326, 1525-1529, doi:10.1126/science.1180353, 2009.

Kassianov, E., Pekour, M., and Barnard, J.: Aerosols in central California: Unexpectedly large contribution of coarse mode 
to aerosol radiative forcing, Geophys. Res. Lett., 39, L20806, doi:10.1029/2012GL053469, 2012.

Koehler, K. A., Kreidenweis, S. M., DeMott, P. J., Petters, M. D., Prenni, A. J., and Carrico, C. M.: Hygroscopicity and cloud droplet activation of mineral dust aerosol, Geophys. Res. Lett., 36, L08805, doi:10.1029/2009GL037348, 2009.

Laborde, M., Mertes, P., Zieger, P., Dommen, J., Baltensperger, U., and Gysel, M.: Sensitivity of the Single Particle Soot Photometer to different black carbon types, Atmos. Meas. Tech., 5, 10311043, doi:10.5194/amt-5-1031-2012, 2012a.

Laborde, M., Schnaiter, M., Linke, C., Saathoff, H., Naumann, K.H., Möhler, O., Berlenz, S., Wagner, U., Taylor, J. W., Liu, D., Flynn, M., Allan, J. D., Coe, H., Heimerl, K., Dahlkötter, F., Weinzierl, B., Wollny, A. G., Zanatta, M., Cozic, J., Laj, P., Hitzenberger, R., Schwarz, J. P., and Gysel, M.: Single Particle Soot Photometer intercomparison at the AIDA chamber, Atmos. Meas. Tech., 5, 3077-3097, doi:10.5194/amt-5-3077-2012, $2012 b$.

Lambe, A. T., Onasch, T. B., Massoli, P., Croasdale, D. R., Wright, J. P., Ahern, A. T., Williams, L. R., Worsnop, D. R., Brune, W. H., and Davidovits, P.: Laboratory studies of the chemical composition and cloud condensation nuclei $(\mathrm{CCN})$ activity of secondary organic aerosol (SOA) and oxidized primary organic aerosol (OPOA), Atmos. Chem. Phys., 11, 8913-8928, doi:10.5194/acp11-8913-2011, 2011.

Langridge, J. M., Richardson, M. S., Lack, D., Law, D., and Murphy, D. M.: Aircraft Instrument for Comprehensive Characterization of Aerosol Optical Properties, Part I: Wavelength-Dependent Optical Extinction and Its Relative Humidity Dependence Measured Using Cavity Ringdown Spectroscopy, Aerosol Sci. Technol., 45, 1305-1318, doi:10.1080/02786826.2011.592745, 2011.

Levin, E. J. T., Prenni, A. J., Palm, B. B., Day, D. A., CampuzanoJost, P., Winkler, P. M., Kreidenweis, S. M., DeMott, P. J., Jimenez, J. L., and Smith, J. N.: Size-resolved aerosol composition and its link to hygroscopicity at a forested site in Colorado, Atmos. Chem. Phys., 14, 2657-2667, doi:10.5194/acp-14-26572014, 2014.

Massoli, P., Bates, T. S., Quinn, P. K., Lack, D. A., Baynard, T., Lerner, B. M., Tucker, S. C., Brioude, J., Stohl, A., and Williams, E. J.: Aerosol optical and hygroscopic properties during TexAQS-GoMACCS 2006 and their impact on aerosol direct radiative forcing, J. Geophys. Res.-Atmos., 114, D00F07, doi:10.1029/2008jd011604, 2009.

Massoli, P., Lambe, A. T., Ahern, A. T., Williams, L. R., Ehn, M., Mikkila, J., Canagaratna, M. R., Brune, W. H., Onasch, T. B., Jayne, J. T., Petaja, T., Kulmala, M., Laaksonen, A., Kolb, C. E., Davidovits, P., and Worsnop, D. R.: Relationship between aerosol oxidation level and hygroscopic properties of laboratory generated secondary organic aerosol (SOA) particles, Geophys. Res. Lett., 37, L24801, doi:10.1029/2010GL045258, 2010.

Mei, F., Hayes, P. L., Ortega, A., Taylor, J. W., Allan, J. D., Gilman, J., Kuster, W., de Gouw, J., Jimenez, J. L., and Wang, J.: Droplet activation properties of organic aerosols observed at an urban site during CalNex-LA, J. Geophys. Res.-Atmos., 118, 2903-2917, doi:10.1002/jgrd.50285, 2013.

Mikhailov, E. F., Vlasenko, S. S., Podgorny, I. A., Ramanathan, V., and Corrigan, C. E.: Optical properties of soot-water drop agglomerates: An experimental study, J. Geophys. Res.-Atmos., 111, D07209, doi:10.1029/2005JD006389, 2006.
Müller, T., Nowak, A., Wiedensohler, A., Sheridan, P., Laborde, M., Covert, D. S., Marinoni, A., Imre, K., Henzing, B., Roger, J.-C., dos Santos, S. M., Wilhelm, R., Wang, Y.-Q., and de Leeuw, G.: Angular Illumination and Truncation of Three Different Integrating Nephelometers: Implications for Empirical, Size-Based Corrections, Aerosol Sci. Technol., 43, 581-586, doi:10.1080/02786820902798484, 2009.

Murphy, D. M., Cziczo, D. J., Froyd, K. D., Hudson, P. K., Matthew, B. M., Middlebrook, A. M., Peltier, R. E., Sullivan, A., Thomson, D. S., and Weber, R. J.: Single-particle mass spectrometry of tropospheric aerosol particles, J. Geophys. Res.-Atmos., 111, D23S32, doi:10.1029/2006JD007340, 2006.

Pekour, M. S., Schmid, B., Chand, D., Hubbe, J. M., Kluzek, C. D., Nelson, D. A., Tomlinson, J. M., and Cziczo, D. J.: Development of a New Airborne Humidigraph System, Aerosol Sci. Technol., 47, 201-207, doi:10.1080/02786826.2012.741274, 2012.

Petters, M. D. and Kreidenweis, S. M.: A single parameter representation of hygroscopic growth and cloud condensation nucleus activity, Atmos. Chem. Phys., 7, 1961-1971, doi:10.5194/acp-71961-2007, 2007.

Prather, K. A., Bertram, T. H., Grassian, V. H., Deane, G. B., Stokes, M. D., DeMott, P. J., Aluwihare, L. I., Palenik, B. P., Azam, F., Seinfeld, J. H., Moffet, R. C., Molina, M. J., Cappa, C. D., Geiger, F. M., Roberts, G. C., Russell, L. M., Ault, A. P., Baltrusaitis, J., Collins, D. B., Corrigan, C. E., Cuadra-Rodriguez, L. A., Ebben, C. J., Forestieri, S. D., Guasco, T. L., Hersey, S. P., Kim, M. J., Lambert, W. F., Modini, R. L., Mui, W., Pedler, B. E., Ruppel, M. J., Ryder, O. S., Schoepp, N. G., Sullivan, R. C., and Zhao, D. F.: Bringing the ocean into the laboratory to probe the chemical complexity of sea spray aerosol, P. Natl. Acad. Sci USA, 110, 7550-7555, doi:10.1073/pnas.1300262110, 2013.

Quinn, P. K., Bates, T. S., Baynard, T., Clarke, A. D., Onasch, T. B., Wang, W., Rood, M. J., Andrews, E., Allan, J., Carrico, C. M., Coffman, D., and Worsnop, D.: Impact of particulate organic matter on the relative humidity dependence of light scattering: A simplified parameterization, Geophys. Res. Lett., 32, L2280, doi:10.1029/2005GL024322, 2005.

Quinn, P. K., Bates, T. S., Schulz, K. S., Coffman, D. J., Frossard, A. A., Russell, L. M., Keene, W. C., and Kieber, D. J.: Contribution of sea surface carbon pool to organic matter enrichment in sea spray aerosol, Nat. Geosci., 7, 228-232, doi:10.1038/ngeo2092, 2014.

Riemer, N., West, M., Zaveri, R., and Easter, R.: Estimating black carbon aging time-scales with a particle-resolved aerosol model, J. Aerosol Sci., 41, 143-158, doi:10.1016/j.jaerosci.2009.08.009, 2010.

Schnaiter, M., Linke, C., Mohler, O., Naumann, K. H., Saathoff, H., Wagner, R., Schurath, U., and Wehner, B.: Absorption amplification of black carbon internally mixed with secondary organic aerosol, J. Geophys. Res.-Atmos., 110, D19204, doi:10.1029/2005JD006046, 2005.

Schwarz, J. P., Spackman, J. R., Gao, R. S., Perring, A. E., Cross, E., Onasch, T. B., Ahern, A., Wrobel, W., Davidovits, P., Olfert, J., Dubey, M. K., Mazzoleni, C., and Fahey, D. W.: The Detection Efficiency of the Single Particle Soot Photometer, Aerosol Sci. Technol., 44, 612-628, doi:10.1080/02786826.2010.481298, 2010.

Setyan, A., Zhang, Q., Merkel, M., Knighton, W. B., Sun, Y., Song, C., Shilling, J. E., Onasch, T. B., Herndon, S. C., Worsnop, D. R., 
Fast, J. D., Zaveri, R. A., Berg, L. K., Wiedensohler, A., Flowers, B. A., Dubey, M. K., and Subramanian, R.: Characterization of submicron particles influenced by mixed biogenic and anthropogenic emissions using high-resolution aerosol mass spectrometry: results from CARES, Atmos. Chem. Phys., 12, 8131-8156, doi:10.5194/acp-12-8131-2012, 2012.

Setyan, A., Song, C., Merkel, M., Knighton, W. B., Onasch, T. B., Canagaratna, M. R., Worsnop, D. R., Wiedensohler, A., Shilling, J. E., and Zhang, Q.: Chemistry of new particle growth in mixed urban and biogenic emissions - insights from CARES, Atmos. Chem. Phys., 14, 6477-6494, doi:10.5194/acp-14-6477-2014, 2014.

Shilling, J. E., Zaveri, R. A., Fast, J. D., Kleinman, L., Alexander, M. L., Canagaratna, M. R., Fortner, E., Hubbe, J. M., Jayne, J. T., Sedlacek, A., Setyan, A., Springston, S., Worsnop, D. R., and Zhang, Q.: Enhanced SOA formation from mixed anthropogenic and biogenic emissions during the CARES campaign, Atmos. Chem. Phys., 13, 2091-2113, doi:10.5194/acp-13-20912013, 2013.

Titos, G., Jefferson, A., Sheridan, P. J., Andrews, E., Lyamani, H., Alados-Arboledas, L., and Ogren, J. A.: Aerosol light-scattering enhancement due to water uptake during the TCAP campaign, Atmos. Chem. Phys., 14, 7031-7043, doi:10.5194/acp-14-70312014, 2014.

Zaveri, R. A., Barnard, J. C., Easter, R. C., Riemer, N., and West, M.: Particle-resolved simulation of aerosol size, composition, mixing state, and the associated optical and cloud condensation nuclei activation properties in an evolving urban plume, J. Geophys. Res.-Atmos., 115, D17210, doi:10.1029/2009jd013616, 2010.

Zaveri, R. A., Shaw, W. J., Cziczo, D. J., Schmid, B., Ferrare, R. A., Alexander, M. L., Alexandrov, M., Alvarez, R. J., Arnott, W. P., Atkinson, D. B., Baidar, S., Banta, R. M., Barnard, J. C., Beranek, J., Berg, L. K., Brechtel, F., Brewer, W. A., Cahill, J. F., Cairns, B., Cappa, C. D., Chand, D., China, S., Comstock, J. M., Dubey, M. K., Easter, R. C., Erickson, M. H., Fast, J. D., Floerchinger, C., Flowers, B. A., Fortner, E., Gaffney, J. S., Gilles, M. K., Gorkowski, K., Gustafson, W. I., Gyawali, M., Hair, J., Hardesty, R. M., Harworth, J. W., Herndon, S., Hiranuma, N., Hostetler, C., Hubbe, J. M., Jayne, J. T., Jeong, H., Jobson, B. T., Kassianov, E. I., Kleinman, L. I., Kluzek, C., Knighton, B., Kolesar, K. R., Kuang, C., Kubátová, A., Langford, A. O., Laskin, A., Laulainen, N., Marchbanks, R. D., Mazzoleni, C., Mei, F., Moffet, R. C., Nelson, D., Obland, M. D., Oetjen, H., Onasch, T. B., Ortega, I., Ottaviani, M., Pekour, M., Prather, K. A., Radney, J. G., Rogers, R. R., Sandberg, S. P., Sedlacek, A., Senff, C. J., Senum, G., Setyan, A., Shilling, J. E., Shrivastava, M., Song, C., Springston, S. R., Subramanian, R., Suski, K., Tomlinson, J., Volkamer, R., Wallace, H. W., Wang, J., Weickmann, A. M., Worsnop, D. R., Yu, X.-Y., Zelenyuk, A., and Zhang, Q.: Overview of the 2010 Carbonaceous Aerosols and Radiative Effects Study (CARES), Atmos. Chem. Phys., 12, 7647-7687, doi:10.5194/acp-12-7647-2012, 2012.
Zelenyuk, A., Yang, J., Choi, E., and Imre, D.: SPLAT II: An Aircraft Compatible, Ultra-Sensitive, High Precision Instrument for In-Situ Characterization of the Size and Composition of Fine and Ultrafine Particles, Aerosol Sci. Technol., 43, 411-424, doi:10.1080/02786820802709243, 2009.

Zhang, Q., Jimenez, J. L., Canagaratna, M. R., Ulbrich, I. M., Ng, N. L., Worsnop, D. R., and Sun, Y. L.: Understanding atmospheric organic aerosols via factor analysis of aerosol mass spectrometry: a review, Anal. Bioanal. Chem., 401, 3045-3067, doi:10.1007/s00216-011-5355-y, 2011.

Zhang, X., Massoli, P., Quinn, P. K., Bates, T. S., and Cappa, C. D.: Hygroscopic growth of submicron and supermicron aerosols in the marine boundary layer, J. Geophys. Res.-Atmos., 119, 83848399, doi:10.1002/2013JD021213, 2014.

Zieger, P., Fierz-Schmidhauser, R., Gysel, M., Ström, J., Henne, S., Yttri, K. E., Baltensperger, U., and Weingartner, E.: Effects of relative humidity on aerosol light scattering in the Arctic, Atmos. Chem. Phys., 10, 3875-3890, doi:10.5194/acp-10-38752010, 2010.

Zieger, P., Fierz-Schmidhauser, R., Weingartner, E., and Baltensperger, U.: Effects of relative humidity on aerosol light scattering: results from different European sites, Atmos. Chem. Phys., 13, 10609-10631, doi:10.5194/acp-13-10609-2013, 2013. 